\title{
Investigating the effects of structural pounding on the seismic performance of adjacent RC and steel MRFs
}

\author{
F. Kazemi ${ }^{1} \cdot$ M. Miari ${ }^{2}$ (D) R. Jankowski ${ }^{2}$
}

Received: 31 July 2020 / Accepted: 13 October 2020 / Published online: 6 November 2020 (c) The Author(s) 2020

\begin{abstract}
An insufficient separation distance between adjacent buildings is the main reason for structural pounding during severe earthquakes. The lateral load resistance system, fundamental natural period, mass, and stiffness are important factors having the influence on collisions between two adjacent structures. In this study, 3-, 5- and 9-story adjacent reinforced concrete and steel moment resisting frames (MRFs) were considered to investigate the collision effects and to determine modification factors for new and already existing buildings. For this purpose, incremental dynamic analysis was used to assess the seismic limit state capacity of the structures using a developed algorithm in OpenSees software including two near-field record subsets suggested by FEMA-P695. The results of this paper can help engineers to approximately estimate the performance levels of MRFs due to pounding phenomenon. The results confirm that collisions can lead to the changes in performance levels, which are difficult to be considered during the design process. In addition, the results of the analyses illustrate that providing a fluid viscous damper between adjacent reinforced concrete and steel structures can be effective to eliminate the sudden changes in the lateral force during collision. This approach can be successfully used for retrofitting adjacent structures with insufficient in-between separation distances.
\end{abstract}

Keywords Seismic collapse capacity $\cdot$ Seismic retrofit $\cdot$ Modification factor $\cdot$ Structural pounding $\cdot$ Incremental dynamic analysis

\section{Introduction}

The seismic design of structures is usually performed for a single structure, neglecting the existence of any adjacent one. Meanwhile, many studies show that pounding between adjacent structures during earthquakes can impose unexpected additional impact force (Sołtysik and Jankowski 2013; Elwardany et al. 2019; Rezaei et al. 2020; Miari et al. 2020). This

M. Miari

mahmoud-miari@hotmail.com; mahmoud.miari@pg.edu.pl

1 Department of Civil Engineering, Faculty of Engineering and Technology, Imam Khomeini International University, PO Box 34149-16818, Qazvin, Iran

2 Faculty of Civil and Environmental Engineering, Gdańsk University of Technology, ul. Narutowicza 11/12, 80-233 Gdańsk, Poland 
load may result in extensive damages or even lead to complete structural destruction (Cole et al. 2012). The structural pounding hazard is taken into account in the latest versions of seismic codes by introducing the minimum separation distance between adjacent buildings. However, several structures were constructed in the past without sufficient in-between separation (see Fig. 1 for example). Moreover, due to the high prices of land in populated areas, leaving unused space between structures is not a good solution from the economical point of view. Although provisions prescribe proper separation distance to avoid collisions, some inherent factors make this separation distance not always effective. Eccentric contact forces due to pounding may lead to torsional movements, which can cause crucial damage in structures (Karayannis and Naoum 2018).

Structural pounding can be categorized as the floor-to-floor pounding (Kazemi et al. 2020,2018a; Cole et al. 2010), floor-to-column pounding (Cole et al. 2010; Kazemi et al. 2018a; Karayannis and Favvata 2005; Efraimiadou et al. 2013; Favvata 2017), eccentric or non-eccentric pounding (Cole et al. 2010; Leibovich et al. 1996; Polycarpou et al. 2014), the un-equal weight of adjacent pounding (Kazemi et al. 2020; Mohebi et al. 2018; Jankowski 2010), and pounding between buildings in series (Skrekas et al. 2014; Raheem et al. 2019). In particular, Karayannis and Favvata (Karayannis and Favvata 2005) investigated interactions between adjacent reinforced concrete structures with different story heights, where the slab of the shorter structure collides with the columns of the taller one. Such collisions lead to the increase in shear forces of the columns at and above the collision level and, because of that, the shear strength in the columns may be exceeded. Indeed, the columns experiencing pounding experience also significant increase in the ductility demands and the available ductility may also be exceeded in the building.

The type of pounding can play an important role in structural damage observed during earthquakes. For example, in the Christchurch 2011 earthquake, damages due to floor-tofloor and floor-to-column pounding were observed more than three times often in comparison to the expected Taipei earthquake (Cole et al. 2012; Jeng and Tzeng 2000; Miari et al. 2019). On the other hand, cases of pounding between adjacent shorter and taller structures in the Taipei earthquake can be expected more than two times often than during the

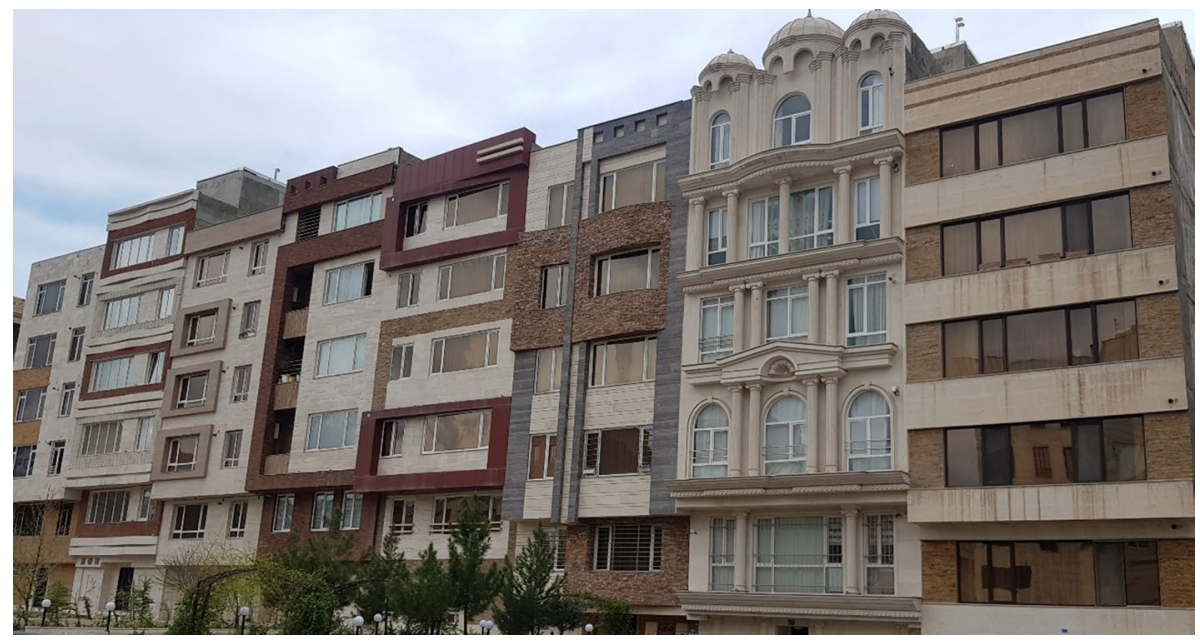

Fig. 1 Adjacent buildings in Tehran with different floors and base levels without separation distance 
Christchurch earthquake. The pounding phenomenon can amplify the seismic response of flexible or stiffer structures depending on their dynamic properties. Some studies also indicate that the stiffer structure response is amplified in a high-frequency range of earthquakes, while the flexible structure response is amplified in the low-frequency range of earthquakes (Dimitrakopoulos et al. 2009,2010). In fact, the vibration frequencies of adjacent structures and the frequency of ground motion play a key role in the seismic response of flexible or stiffer structural response (Chenna and Ramancharla 2018). Therefore, it is possible to predict the seismic response of flexible or stiffer adjacent structures having an appropriate frequency range.

Several researchers have studied the effect of building materials on the poundinginvolved structural response during earthquakes. It has been shown that different materials lead to different responses and some are critical than the others. For instance, Jankowski (2010) studied the response of two adjacent towers with different materials using the shaking table tests. It was found that the steel towers experienced the highest peak displacement, followed by concrete and ceramic towers, while the timber structures experienced a reduction of the displacement as compared to the case when the two towers vibrate separately. Favvata et al. (2013) studied the effect of the material type on different dynamic properties. Two material types (concrete and steel) were considered. It was concluded that the RC structures were mostly affected at the top columns regarding flexural and ductility demands and the bottom columns regarding shear and ductility demands.

It is obvious that the simplest way to prevent pounding is to provide appropriate separation distance between buildings. However, for existing structures without in-between separation, an alternative way to eliminate collisions should be used. Several methods have been proposed to strengthen the exciting buildings against pounding. The use of collision shear walls and bracing systems is among the most effective methods (Nair 2016; Jamal and Vidyadhara 2013; Hameed et al. 2012; Barros and Khatami 2012; Anagnostopoulos and Karamaneas 2008a,b). The approach decreases the maximum out-of-phase displacement, the maximum displacement, the number of impacts and the ductility demands. Another method considers the implementation of some impact-absorbing materials between the structures to decrease the high acceleration spikes. That can be obtained by using rubber shock absorbers (Polycarpou et al. 2013; Lin and Weng 2001; Takabatake et al. 2014), polystyrene bumpers (Rezavandi and Moghadam 2007; Rezavani and Moghadam 2004) and polymer elements (Sołtysik et al. 2017, 2020). Moreover, another technique is to link the adjacent buildings together so that they vibrate in-phase and hence pounding is prevented. Several types of links were studied, including viscous dampers (Patel and Jangid 2010), multi-link viscoelastic systems (Tubaldi et al. 2012), friction dampers (Licari et al. 2015), tuned mass dampers (Bekdaş and Nigdeli 2012) and fluid viscous dampers (Pratesi et al. 2013, 2014; Sorace and Terenzi 2013; Kazemi et al. 2018b). The links should be installed at certain levels of the structures, where the impacts are expected (Cole et al. 2012; Jankowski and Mahmoud 2016).

This study is focused on predicting the performance levels of adjacent Reinforced Concrete (RC) and steel structures. The main purpose is to evaluate the effects of pounding on the seismic response of two adjacent structures in order to determine proper modification factors for already existing buildings and new ones, providing practical tool for estimating pounding influence on the seismic performance levels. For this purpose, three types of equal-height $\mathrm{RC}$ and steel buildings were considered in the study, assuming three separation distances between them. Also, a linear viscoelastic contact element was selected to model the pounding phenomenon. The investigation was conducted with a developed computer program code to model both adjacent structures in one model and to perform the 
collapse state analysis subjected to earthquake records. Moreover, the influence of using Fluid Viscous Dampers (FVDs) between two structures was also investigated, which can be considered as a retrofitting solution to reduce the effects of collisions.

\section{Materials and methods}

\subsection{Modeling of adjacent RC and steel structures}

The study was focused on the investigation of the effects of pounding on the limit state capacity of adjacent 3-, 5- and 9-story RC and steel Moment Resisting Frames (MRFs). The structures (see Fig. 2 for their plan) were assumed to be located in California with soil class $\mathrm{D}$ and seismic design parameters of $S D_{S}=1.0 \mathrm{~g}$ and $S D_{1}=0.6 \mathrm{~g}$ (g is the acceleration of gravity). In this study, the 3-, 5- and 9-story steel MRFs were designed according to the Load and Resistance Factor (LRFD) based on ASCE/SEI 7-16 (2017), ANSI/AISC 360-16 (2016) and ANSI/AISC 341-10 (2016) using Kitayama and Constantinou (2018) procedures. Also, the 3-, 5- and 9-story RC MRFs were designed according to the criteria of the ACI 318-14 (2014) using Haselton and Deierlein (2007) methods.

The response modification factor of $R=8$, system over-strength factor of $\Omega=3$, and the deflection amplification factor of $C_{d}=5.5$ were selected for both RC and steel MRFs. Besides, the floor dead and live loads of $8.379 \mathrm{kN} / \mathrm{m}^{2}$ and $2.39 \mathrm{kN} / \mathrm{m}^{2}$ were applied to the structures, respectively. Young's modulus of $200 \mathrm{GPa}$ and the yield strength of $345 \mathrm{MPa}$ were assumed for steel structures, and the concrete compressive strength was considered as equal to $34.5 \mathrm{MPa}$. It is worth mentioning that all columns, except for those in the MRFs (see thick lines in Fig. 2), were assumed as gravity columns and modeled as leaning columns. In Fig. 2, the tributary area for calculating the gravity loads applied to the leaning column and the frame columns is presented. A pinned leaning column with gravity loads was linked with rigid beams to simulate P-delta effect. In order to consider this effect, a leaning column was modeled to be pinned at the base and connected to the frame at floor levels using axially rigid links (see Fig. 3). The gravity loads (including those applied to the leaning columns) was based on Fig. 2. This approach to consider the P-delta effect in the analysis has recently been used in a number of studies (see Asgarkhani et al. 2020; Yakhchalian et al. 2020; Mohebi et al. 2020, for example). In steel models, structural members of beams and columns were modeled by a nonlinear rotational spring at both ends of each element with zero length. This spring represents deteriorating moment-rotation hysteresis using the modified Ibarra-Krawinkler bilinear-hysteretic model (Kazemi et al.

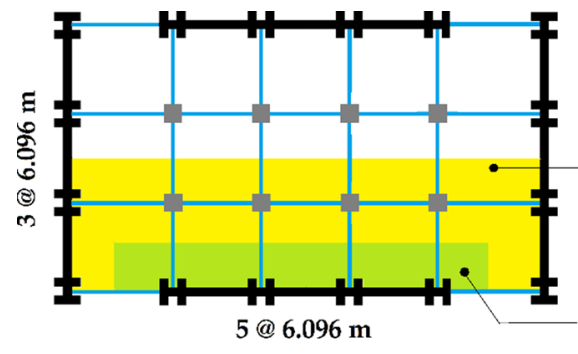

Tributary area for gravity loads applied to the leaning column

Tributary area for gravity loads applied to the frame columns

Fig. 2 Plan of the considered RC and steel MRFs 

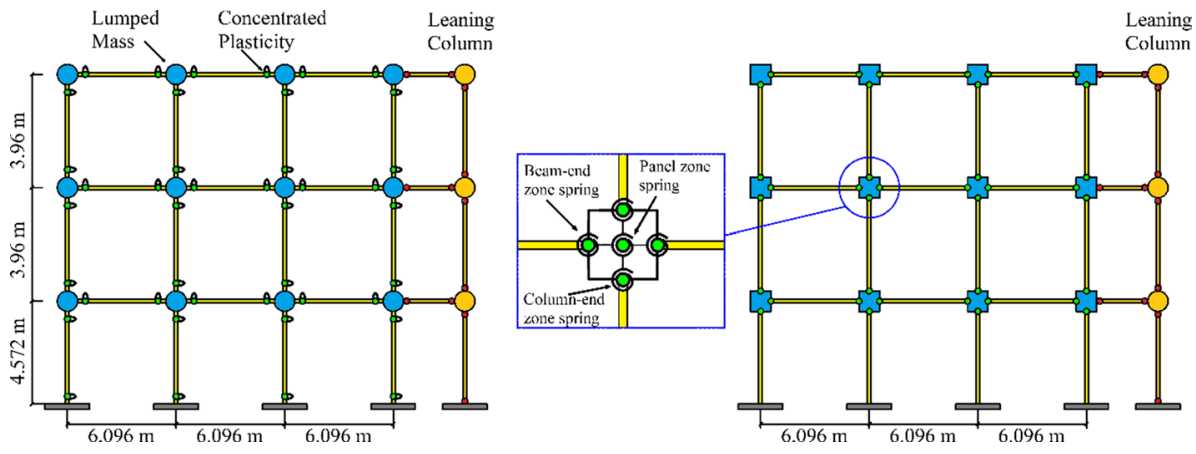

Fig. 3 Lumped mass and concentrated plasticity model for a 3-story steel MRF and beam-column joints in a 3-story RC MRF considering panel zone

2018a; Lignos and Krawinkler 2010). For RC models, the procedure introduced by Deierlein et al. (2005) was used to capture the deterioration and collapse modes. The element model that captures monotonic and cyclic modes of deterioration was developed and implemented into OpenSees (McKenna et al. 2016) by Ibarra et al. (2005) and Altoontash (2004), respectively. Figure 3 presents the lumped mass and concentrated plasticity model for a 3-story steel MRF and beam-column joints in a 3-story RC MRF considering panel zone. Moreover, section properties and geometry of the designed RC and steel MRFs are presented in Figs. 4 and 5. The design documentations of the columns and beams of RC structures are presented in Tables 1 and 2.

\subsection{Impact force models}

There are a number of different impact force models which can be used to simulate structural pounding (Polycarpou and Komodromos 2010). In the present study, the linear viscoelastic model, also known as the Kelvin-Voigt model, was applied. The impact force, $F(t)$, in the model is expressed as (Anagnostopoulos 1988):

$$
F(t)=K_{i m p} \delta(t)+C_{i m p} \dot{\delta}(t)
$$

where $\delta(t)$ and $\dot{\delta}(t)$ denote the relative deformation and the relative velocity of colliding structural members, respectively, $K_{i m p}$ and $C_{i m p}$ describe the impact element's stiffness and the damping coefficient of impact element which can be calculated from the formula (Anagnostopoulos 2004):

$$
C_{i m p}=2 \xi \sqrt{K_{i m p} \frac{m_{1} m_{2}}{m_{1}+m_{2}}}
$$

where $m_{1}$ and $m_{2}$ are masses of structural members and $\xi$ is the impact damping ratio correlated with a coefficient of restitution, $e$, by the formula (Anagnostopoulos 1988,2004):

$$
\xi=\frac{-\ln (e)}{\sqrt{\pi^{2}+(\ln e)^{2}}}
$$



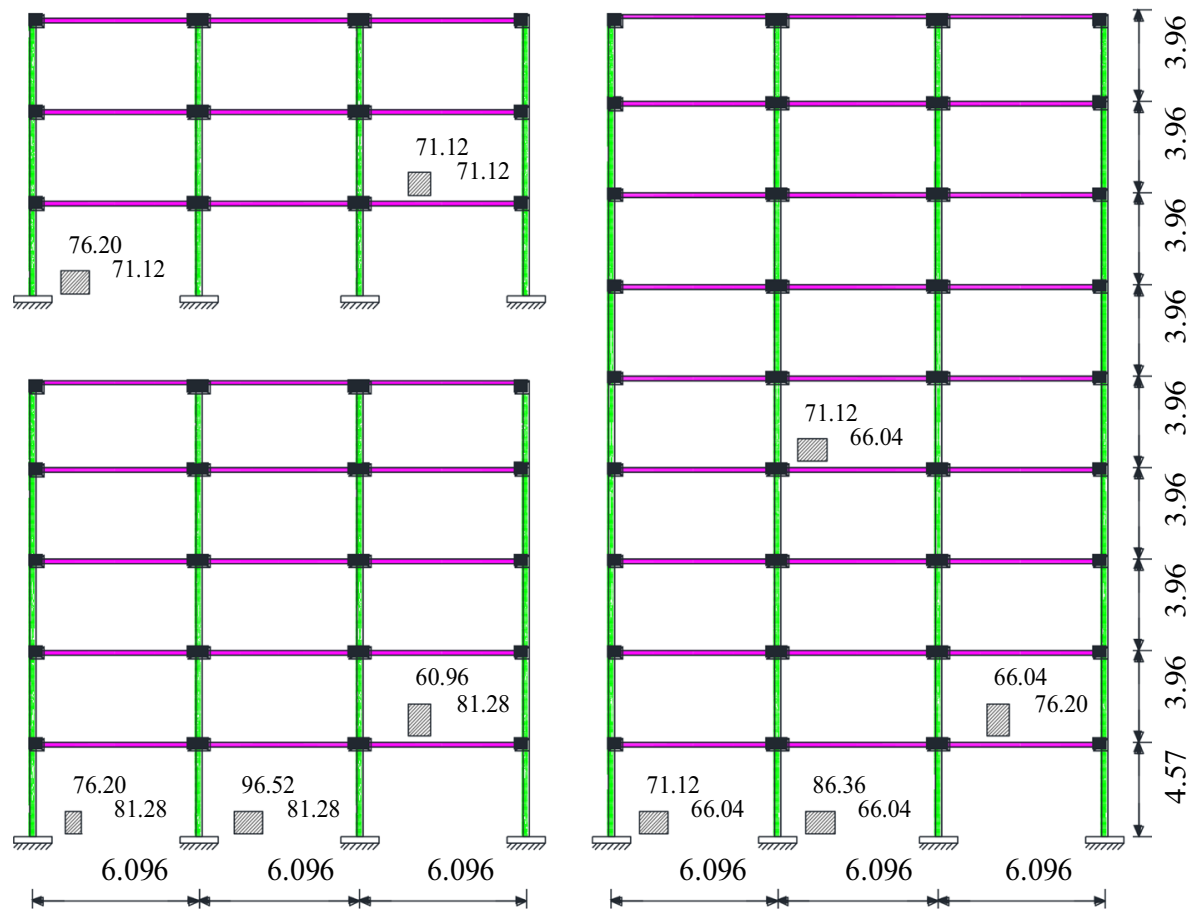

Fig. 4 Section dimensions and geometry of the designed 3-, 5- and 9-story RC MRFs

The coefficient of restitution equal to 0.65 was used in the analysis (see Mahmoud and Jankowski 2009,2011; Polycarpou and Komodromos 2010). The three adjacent structures were assumed to have symmetric plans. Polycarpou et al. (2014) underlined that plan geometry and material characteristics may play a key role in the impact region. Therefore, they proposed a methodology for simulating 3D pounding in the case of adjacent buildings. According to their approach, the normal impact stiffness, $K_{i}$, in the impact region can be calculated as follows (Polycarpou et al. 2014):

$$
\begin{gathered}
K_{i}=\left[\frac{1-v_{1}^{2}}{E_{D y n, 1}}+\frac{1-v_{2}^{2}}{E_{D y n, 2}}\right]^{-1}, \\
E_{D y n, i}=5.82\left(E_{\text {Static }, i}\right)^{0.63}
\end{gathered}
$$

where $\nu_{i}$ is the Poisson's ratio at the contact region and $E_{D y n, i}$, is the dynamic elastic modulus of normal strength concrete that is calculated based on the static elastic modulus, $E_{\text {Static, } i}$ (Salman and Al-Amawee 2006). Using Eqs. (4) and (5), and assuming that $E_{\text {Static }}=21 \mathrm{GPa}$ and $\nu_{i}=0.2$, the normal impact stiffness was calculated to be equal to $K_{i}=20.96 \times 10^{6} \mathrm{kN} / \mathrm{m}^{2}$. Multiplying the normal impact stiffness, $K_{i}$, by half of the length of the pounding zone $(9.144 \mathrm{~m})$ gave the impact stiffness, of $K_{\text {imp }}=1.917 \times 10^{8} \mathrm{kN} / \mathrm{m}$. Moreover, the impact damping coefficient of $C_{k}=7576 \mathrm{kNs} / \mathrm{m}$ was obtained from Eq. (2).

It should be underlined that the calculated values of impact stiffness and damping coefficient were used to model very complicated pounding phenomenon, which may incorporate 

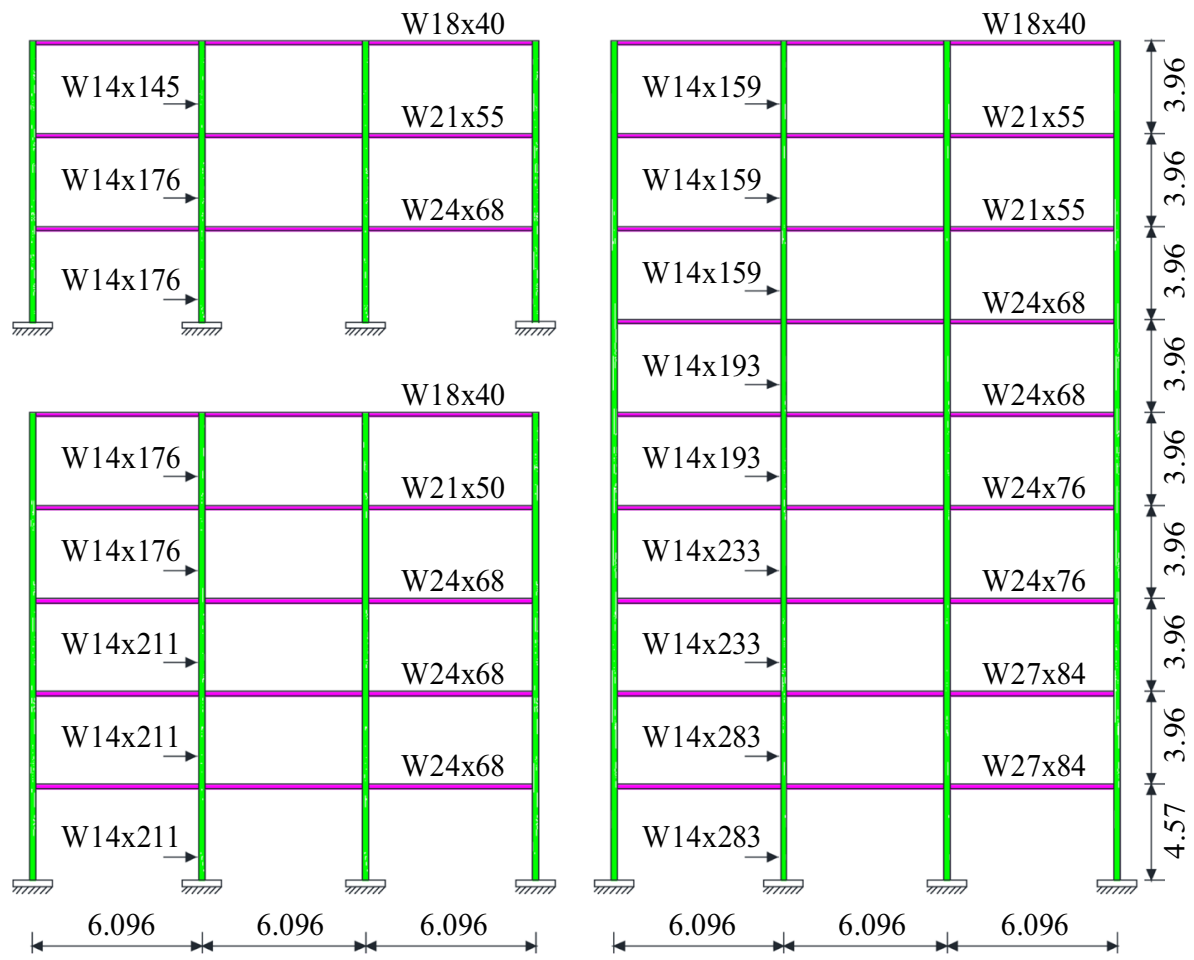

Fig. 5 Section dimensions and geometry of the 3-, 5- and 9-story steel MRFs

such important local effects as inelastic flexural deformations, yielding of the flexural reinforcement, ductility effects or potential shear brittle failure in the contact area. Also, the parameters and the behavior of the spring-damper element can be highly uncertain since geometry of the impact surfaces is not always known, the material under the impact loadings presents uncertain properties depending on the variable impact velocities, etc. Fortunately, it has been observed that different impact stiffness and damping values do not really influence the results considerably (see Karayannis and Naoum 2018 for example). Therefore, the calculated impact stiffness and damping coefficients can be considered as the approximate yet appropriate values to be used in the analysis.

According to ASCE/SEI 7-16 (2017), structural separation distance shall allow for the maximum inelastic response displacement, $\delta_{M}$, and adjacent structures shall be separated at least by the distance $\delta_{M T}=D$ calculated as follows:

$$
\delta_{M T}=D=\sqrt{\left(\frac{C_{d} \cdot \delta_{M}}{I}\right)_{1}^{2}+\left(\frac{C_{d} \cdot \delta_{M}}{I}\right)_{2}^{2}}
$$

where $C_{d}$ is the deflection amplification factor and $I$ is the importance factor. In this research, the maximum inelastic response displacement, $\delta_{M}$, for both RC and steel MRFs were obtained from the base shear-roof displacement curves of the structures using the nonlinear static pushover analyses with lateral load distributions according to the first mode shapes of the structures. Table 3 presents all separation distances for considered adjacent 


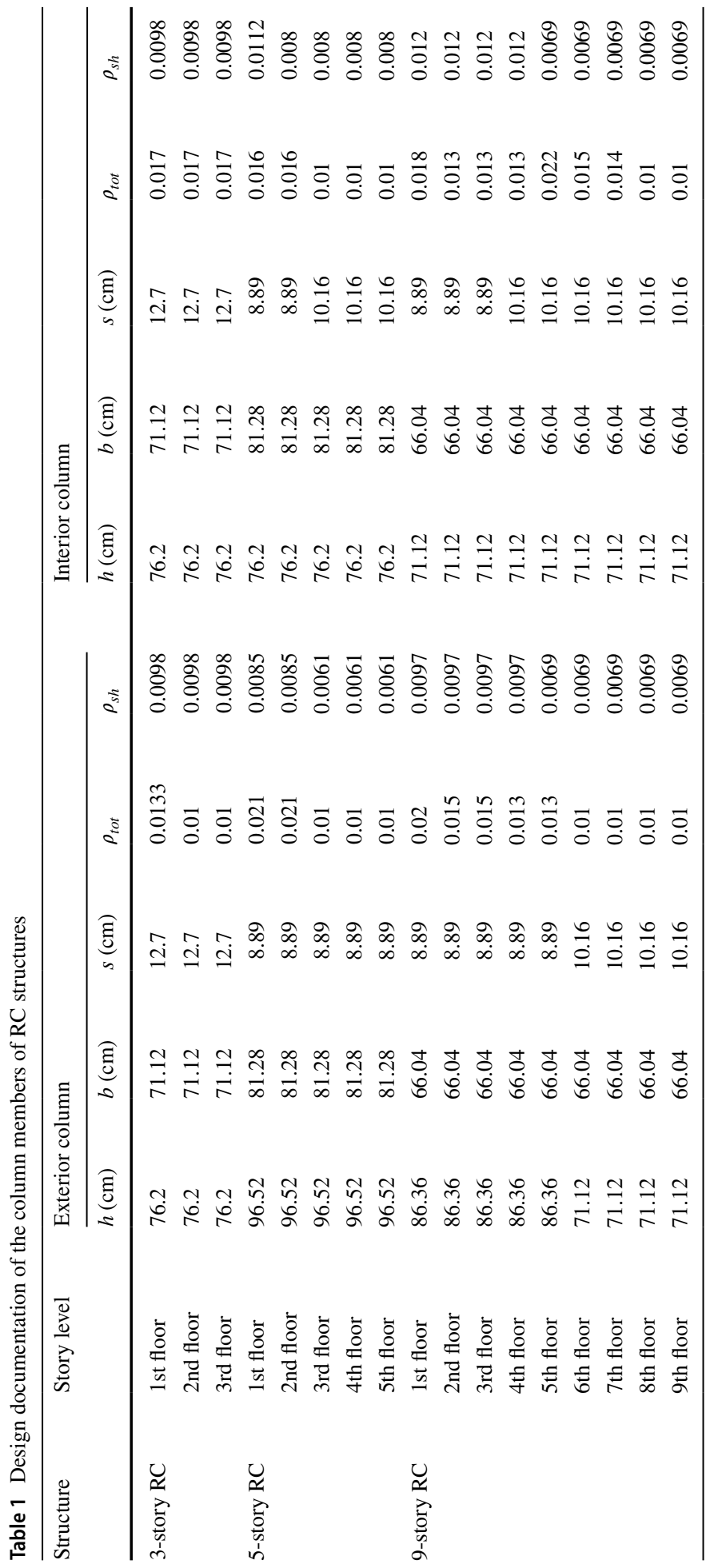


Table 2 Design documentation of the beam members of RC structures

\begin{tabular}{|c|c|c|c|c|c|c|c|}
\hline \multirow[t]{2}{*}{ Structure } & \multirow[t]{2}{*}{ Story level } & \multicolumn{6}{|c|}{ Exterior and interior beam } \\
\hline & & $h(\mathrm{~cm})$ & $b(\mathrm{~cm})$ & $s(\mathrm{~cm})$ & $\rho$ & $\rho^{\prime}$ & $\rho_{s h}$ \\
\hline \multirow[t]{3}{*}{ 3-story RC } & 1st floor & 71.12 & 71.12 & 12.7 & 0.0065 & 0.0075 & 0.0039 \\
\hline & 2nd floor & 71.12 & 71.12 & 12.7 & 0.0065 & 0.0075 & 0.0039 \\
\hline & 3rd floor & 71.12 & 71.12 & 12.7 & 0.0065 & 0.0075 & 0.0039 \\
\hline \multirow[t]{5}{*}{ 5-story RC } & 1st floor & 60.96 & 81.28 & 12.7 & 0.0108 & 0.0123 & 0.0051 \\
\hline & 2nd floor & 60.96 & 81.28 & 12.7 & 0.01 & 0.0115 & 0.0048 \\
\hline & 3rd floor & 60.96 & 81.28 & 12.7 & 0.0093 & 0.0180 & 0.0039 \\
\hline & 4th floor & 60.96 & 81.28 & 12.7 & 0.0048 & 0.0060 & 0.0029 \\
\hline & 5 th floor & 60.96 & 81.28 & 12.7 & 0.0048 & 0.0060 & 0.0029 \\
\hline \multirow[t]{9}{*}{ 9-story RC } & 1st floor & 76.20 & 66.04 & 12.7 & 0.0068 & 0.0075 & 0.0042 \\
\hline & 2nd floor & 76.20 & 66.04 & 16.51 & 0.0073 & 0.0083 & 0.0045 \\
\hline & 3rd floor & 76.20 & 66.04 & 12.7 & 0.0068 & 0.0080 & 0.0043 \\
\hline & 4th floor & 76.20 & 66.04 & 13.97 & 0.0063 & 0.0075 & 0.0041 \\
\hline & 5th floor & 76.20 & 66.04 & 15.24 & 0.0055 & 0.0068 & 0.0037 \\
\hline & 6th floor & 76.20 & 66.04 & 16.51 & 0.0049 & 0.0055 & 0.0031 \\
\hline & 7th floor & 76.20 & 66.04 & 13.97 & 0.0032 & 0.0040 & 0.0025 \\
\hline & 8th floor & 76.20 & 66.04 & 15.24 & 0.0032 & 0.0032 & 0.0024 \\
\hline & 9th floor & 76.20 & 66.04 & 15.24 & 0.0032 & 0.0032 & 0.0024 \\
\hline
\end{tabular}

Table 3 Considered adjacent RC and steel MRFs and separation distance between them

\begin{tabular}{llll}
\hline Structural models & $0.0(\mathrm{~m})$ & $0.5 D(\mathrm{~m})$ & $1.0 D(\mathrm{~m})$ \\
\hline 3-story RC and 3-story steel & 0.0 & 0.083 & 0.166 \\
3-story RC and 5-story steel & 0.0 & 0.077 & 0.155 \\
3-story RC and 9-story steel & 0.0 & 0.074 & 0.147 \\
5-story RC and 3-story steel & 0.0 & 0.088 & 0.176 \\
5-story RC and 5-story steel & 0.0 & 0.129 & 0.259 \\
5-story RC and 9-story steel & 0.0 & 0.138 & 0.275 \\
9-story RC and 3-story steel & 0.0 & 0.83 & 0.166 \\
9-story RC and 5-story steel & 0.0 & 0.125 & 0.250 \\
9-story RC and 9-story steel & 0.0 & 0.216 & 0.431 \\
\hline
\end{tabular}

$\mathrm{RC}$ and steel MRFs.In this research, to investigate the effects of structural separation, three values of the separation distance of $0.0,0.5 \mathrm{D}$ and $1.0 \mathrm{D}$ were assumed. Also, each of the $\mathrm{RC}$ and steel MRFs were analyzed without any adjacent structure.

\subsection{Results and discussion}

\subsubsection{Comparing moment-rotation curves}

The pounding phenomenon can affect the response of the adjacent structures by sudden impacts. Therefore, the plastic hinges of beams and columns may experience a sudden change that may cause an increase in their performance levels. To compare the presence 
of plastic hinges, moment-rotation hysteresis curve of beam and column of the first floor of the 3-story MRF were calculated according to the modified Ibarra-Krawinkler bilinear-hysteretic model (Kazemi et al. 2018a; Lignos and Krawinkler 2010). Then, one record of Pulse-Like (PL) record subsets (Kocaeli Turkey, 8/17/1999, Izmit) suggested by FEMA-P695 (2009) was selected to perform nonlinear time history analysis given that $S_{a}\left(T_{1}\right)=1.34 \mathrm{~g}$. To compare the effects of pounding, two models of isolated 3-story steel MRF and 5-story RC MRF were considered, given a separation distance of 0.0. Figure 6 presents the comparison between the results of the beam and column of the first floor of the 3-story steel MRF for both conditions. According to this figure, pounding can increase the maximum rotation of beam hinge from 0.038 to 0.051 radians, and the maximum rotation of column hinge from 0.034 to 0.048 radians. Increasing the rotation can cause an increase in the performance level of hinges and therefore can lead to an increase in the performance levels of the structure. So, it is important to investigate the effects of the pounding phenomenon in the performance levels of structures, considering different adjacency of short and tall structures. Although the results concern only one of the beams and column hinges of the 3-story steel MRF, similar results have been obtained for all moment-rotation curves of the considered structural models.

\subsubsection{IDA curves}

According to performance-based earthquake engineering, Incremental Dynamic Analysis (IDA) is one of the most commonly used techniques for assessment of the seismic limit state capacity of a structure. It concerns a series of nonlinear time history analyses with different Intensity Measures (IMs). The IM (for this study, selected as $S_{a}\left(T_{1}\right)$ ) increases until the total seismic collapse of the structure. Two sets of 28 earthquakes, including near-field No-Pulse (NP) and PL record subsets suggested by FEMA-P695 (2009), were considered to perform IDAs using a developed Tcl code in MATLAB (2014) and OpenSees (McKenna et al. 2016) software assuming Hunt and Fill algorithm (Vamvatsikos and Cornell 2002). Furthermore, the developed algorithm is capable of analyzing two adjacent structures with real conditions, allowing for the seismic collapse of the structure due to pounding. In fact, this algorithm can remove the collapsed structure during the analysis and capture the limited state capacities of both
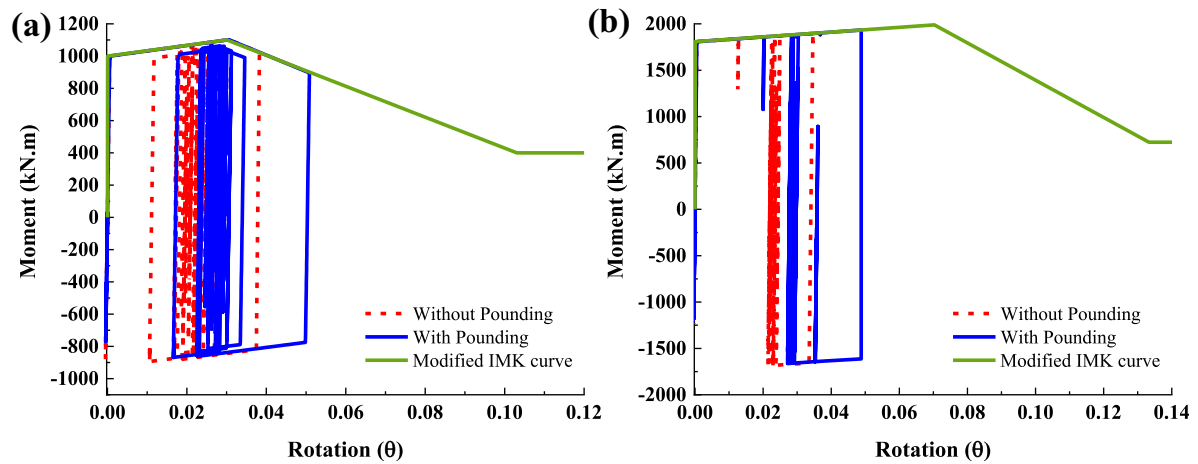

Fig. 6 Comparing hinges of $\mathbf{a}$ beam, and $\mathbf{b}$ column for first floor of the 3-story steel MRF considering pounding with 5-story RC MRF given a separation distance of 0.0 

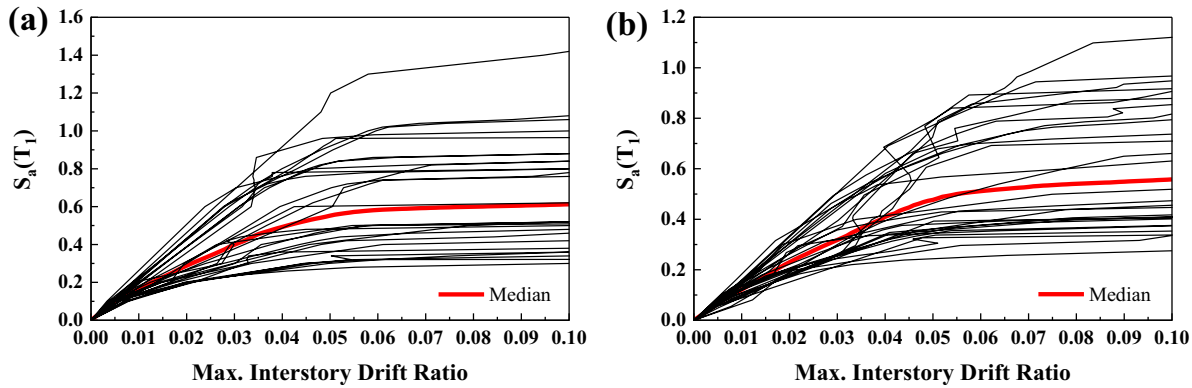

Fig. 7 IDA curves of the 9-story RC and 9-story steel colliding MRFs using near-field PL record subset
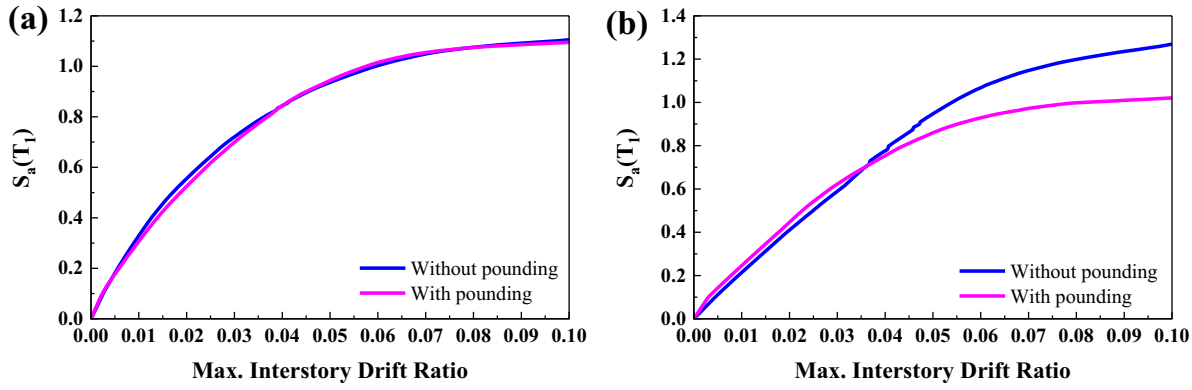

Fig. 8 Comparing the median IDA curves of the, a 3-story RC and, b 5-story steel pounding structures with a separation distance of 0.0 subjected to the PL record subset

pounding structures in one model. In addition to the decrease in the analysis time, it can increase the accuracy of the pounding models by considering the damage of the adjacent structure and its effect after the total collapse of the adjoining structure. Figure $7 \mathrm{a}, \mathrm{b}$ presents the IDA curves of the 9-story RC and 9-story steel MRFs colliding structures subjected to the near-field PL record subset, respectively.

Figure 8a, b presents the median IDA curve of 3-story RC MRF pounding with 5-story steel MRF, considering separation distance of 0.0, including the PL record subset. It is shown that there is no change in the median IDA curve of the 3-story RC MRF due to the pounding effect, but the median IDA curve of the 5-story steel MRF decreases by $15.9 \%$ (from 1.269 to 1.066). According to Fig. 9a, b, after replacing shorter RC MRF (i.e. 3-story RC) with a taller one (i.e. 9-story RC), the median IDA curve of the 5-story steel MRF decreases by $8.1 \%$ (from 1.269 to 1.166 ). On the contrary, the 9-story RC MRF has experienced a $16.43 \%$ increase in the median IDA curve (from 0.529 to 0.633 ). As a result, the steel structure is sensitive to the height of the adjacent structure, but in both cases, the median IDA curve decreases. Moreover, the tall RC structure will achieve higher values of the median IDA curve due to the adjacency of shorter steel structures.

The median IDA curves of the 5-story RC structure with adjacent the 3-, and 9-story steel structures are presented in Figs. 10 and 11. We can see that the median IDA curve of the 5-story RC structure colliding with the 3- and 9-story steel structures increases by 3.3\% (from 0.987 to 1.021 ) and by $29.95 \%$ (from 0.987 to 1.409 ), respectively. On the other hand, the median IDA curve of the 3-, and 9-story steel structures decreases by $13.53 \%$ and 

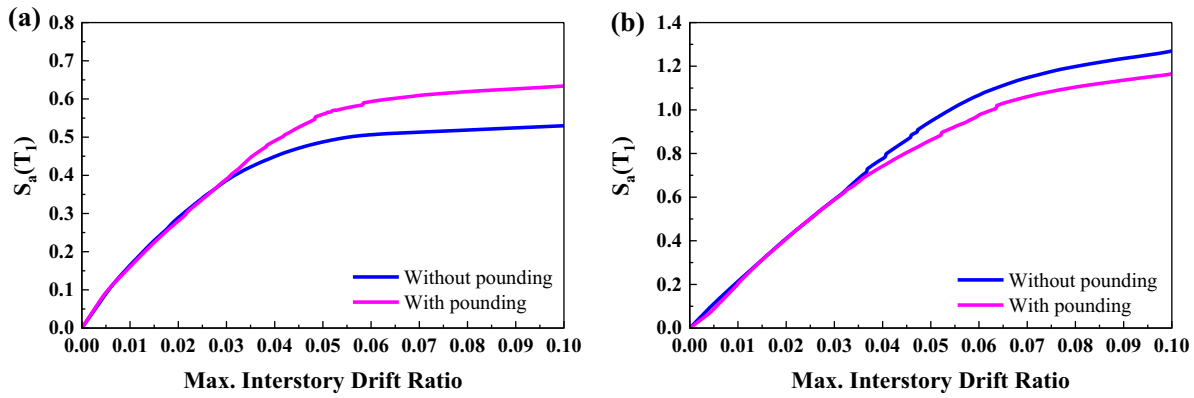

Fig. 9 Comparing the median IDA curves of the, a 9-story RC and, b 5-story steel pounding structures with a separation distance of 0.0 subjected to the PL record subset
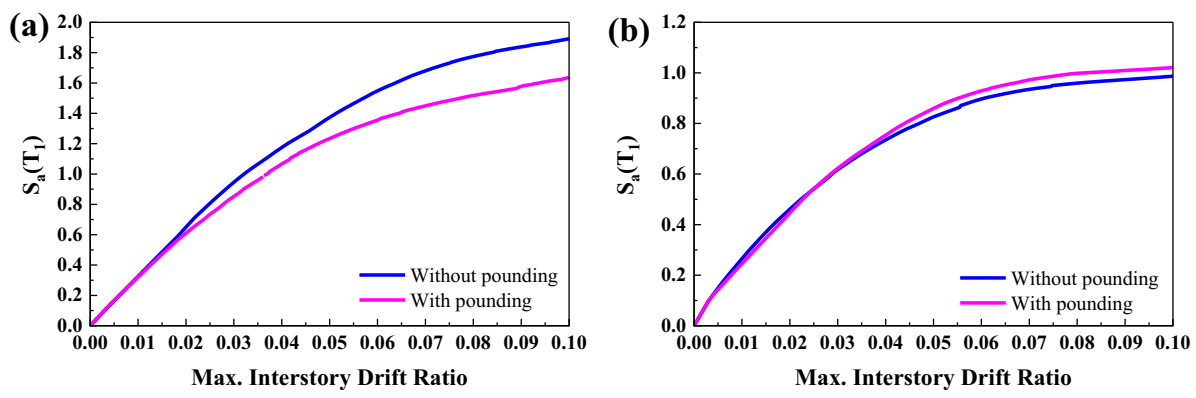

Fig. 10 Comparing the median IDA curves of a 3-story steel and b 5-story RC pounding structures with a separation distance of 0.0 subjected to the PL record subset

(a)

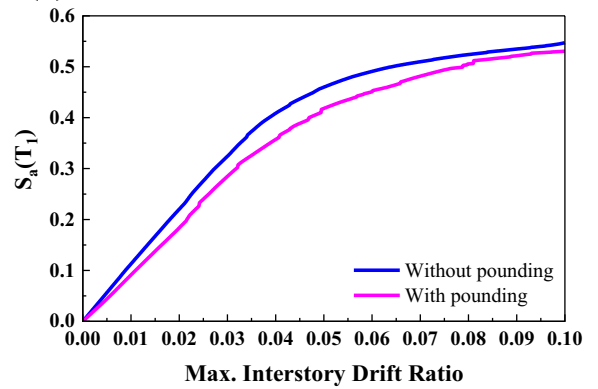

(b)

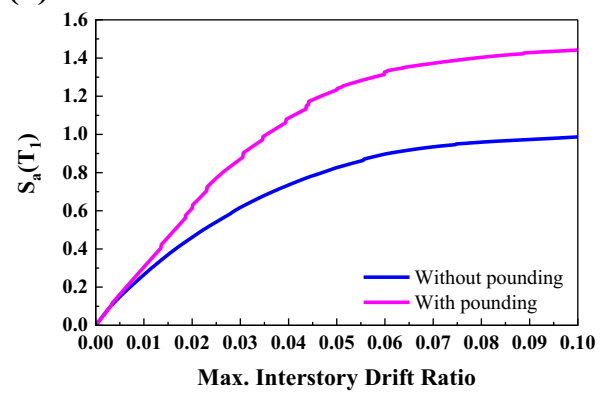

Fig. 11 Comparing the median IDA curves of a 9-story steel and b 5-story RC pounding structures with a separation distance of 0.0 subjected to the PL record subset

by $3.9 \%$, respectively. Hence, shorter (e.g. 3-story steel) or taller (e.g. 9-story steel) structures can lead to the increase in the median IDA curve of the 5-story RC structure, while their median IDA curves decrease correspondingly. 


\subsubsection{Performance level}

Three structural performance levels of Immediate Occupancy (IO), Life Safety (LS), and Collapse Prevention (CP) were considered by FEMA 356 (2000) to describe damage state about specific performance levels. These performance levels are defined based on the fact whether we deal with a primary or secondary member, and whether the member acts as a deformation-control or force-control element. In this study, all elements were considered to be primary members; hence, transient displacement response at story levels was assumed for performance levels. According to FEMA 356 (2000), allowable inter-story drift values of $1.0 \%, 2.0 \%$ and $4.0 \%$ for IO, LS, and CP performance levels were chosen for RC structures, respectively. Also, allowable inter-story drift values of $0.7 \%, 2.5 \%$ and $5.0 \%$ for IO, LS, and CP performance levels were selected for steel MRFs, respectively. Moreover, the seismic collapse Capacity (C) of the RC and steel MRFs were obtained from the flat part of the median IDA curves.

Table 4 presents the limited state capacity of RC and steel MRFs, considering two $\mathrm{NP}$ and PL record subsets. All performance levels were calculated by using allowable inter-story drift values due to FEMA 356 (2000). According to the results, performance levels of RC MRFs subjected to NP subset are higher than for the PL subset. Also, the same result is shown for 3-story steel MRF, whereas in the case of 5-story steel MRF, only the $\mathrm{C}$ level follows the trends and other performance levels including IO, LS, and CP are wise versa. Moreover, according to the results obtained for the 9-story steel MRF, seismic performance levels of the PL subset are higher than for the NP subset.

Table 5 presents the limited state capacities of steel MRFs colliding with adjacent RC MRFs considering separation distance of 0.0 and $1.0 \mathrm{D}$ assuming two record subsets. Comparing the results of 3-story steel MRF with and without pounding, for a given separation distance of 0.0 , shows that pounding increases the performance level of IO (showed by black numbers), while decreases the performance levels of LS, CP, and $\mathrm{C}$. Besides, the red numbers show the reduction in the median IDA curves of the pounding condition, as compared to the isolated structure. The performance levels of the 9-story steel MRFs pounding with 3-, and 9-story RC MRFs with a separation distance of 0.0 increases due to pounding under two record subsets. Similar results are also seen for collisions with 3-, 5-, and 9-story RC MRFs for a separation distance of $1.0 \mathrm{D}$. It should be added that the improvement in performance levels can be an important effect of considering pounding that may help engineers to achieve economic

Table 4 Limited state capacities of the RC and steel MRFs without any adjacent structure subjected to NP and PL record subsets

\begin{tabular}{|c|c|c|c|c|c|c|c|c|c|c|c|c|}
\hline \multirow[t]{2}{*}{ Subset } & IO & LS & $\mathrm{CP}$ & $\mathrm{C}$ & $\mathrm{IO}$ & LS & $\mathrm{CP}$ & $\mathrm{C}$ & $\mathrm{IO}$ & LS & $\mathrm{CP}$ & $\mathrm{C}$ \\
\hline & \multicolumn{4}{|c|}{ 3-story RC } & \multicolumn{4}{|c|}{ 5-story RC } & \multicolumn{4}{|c|}{ 9-story RC } \\
\hline PL & 0.329 & 0.555 & 0.843 & 1.105 & 0.265 & 0.461 & 0.734 & 0.987 & 0.164 & 0.289 & 0.449 & 0.529 \\
\hline $\mathrm{NP}$ & 0.394 & 0.720 & 1.152 & 1.538 & 0.281 & 0.518 & 0.852 & 1.167 & 0.166 & 0.301 & 0.475 & 0.544 \\
\hline \multirow[t]{2}{*}{ Subset } & $\mathrm{IO}$ & LS & $\mathrm{CP}$ & $\mathrm{C}$ & $\mathrm{IO}$ & LS & $\mathrm{CP}$ & $\mathrm{C}$ & $\mathrm{IO}$ & LS & $\mathrm{CP}$ & $\mathrm{C}$ \\
\hline & \multicolumn{4}{|c|}{ 3-story steel } & \multicolumn{4}{|c|}{5 -story steel } & \multicolumn{4}{|c|}{9 -story steel } \\
\hline PL & 0.227 & 0.806 & 1.373 & 1.892 & 0.153 & 0.501 & 0.947 & 1.269 & 0.079 & 0.275 & 0.459 & 0.547 \\
\hline NP & 0.227 & 0.804 & 1.455 & 2.222 & 0.134 & 0.480 & 0.943 & 1.303 & 0.062 & 0.242 & 0.381 & 0.466 \\
\hline
\end{tabular}




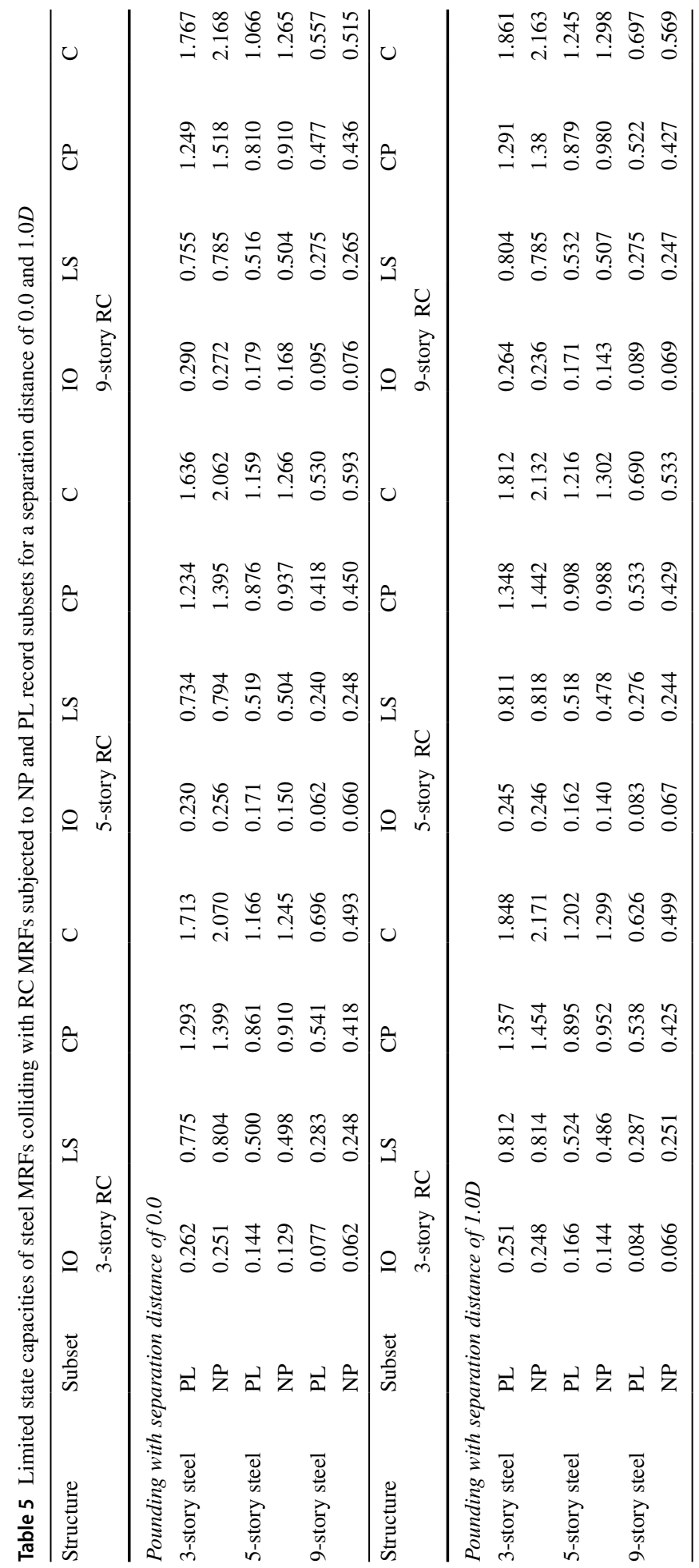


design using some additional capacities. In contrast, the reduction in capacities should be considered in the design process.

Table 6 presents the limited state capacities of RC MRFs colliding with adjacent steel MRFs, for separation distances of 0.0 and $1.0 D$, assuming two record subsets. According to the results, performance levels of the 5-story RC MRF increase for the case of pounding with 3-, 5-, and 9-story steel MRFs for both separation distances and two record subsets. However, in other cases, the performance levels of IO and LS show a decreasing trend. Therefore, these performance levels are more vulnerable to consider the influence of the pounding phenomenon, and the adjacent structures should be considered during the design process. It should be mentioned that the results of pounding for a separation distance of $0.5 \mathrm{D}$ can approximately be obtained by linear interpolation of the results for a separation distance of 0.0 and $1.0 D$, as presented in Tables 5 and 6.

\subsubsection{Seismic fragility curves}

Seismic fragility refers to the possibility of different performance levels in the structure under seismic ground motions (Kazemi et al. 2018b, 2020). Moreover, it describes the relationship between different performance levels and seismic intensities, and it evaluates the collapse probability of the structure to reach or exceed certain performance state under considered seismic events. The probability curve is a good example to be used for comparing the results of structures experienced by pounding. The obtained IDA curves can be used to generate seismic fragility curves for various performance levels characterized by $S_{a}\left(T_{1}\right)$. The schematic of the fragility curves for different performance levels due to pounding between 3-story RC and 5-story steel, based on the IDA curves, are depicted in Fig. 12. According to the results obtained for 3 -story RC MRF, the median $S_{a}\left(T_{1}\right)$ corresponds to the probability of $50 \%$ in the case of the seismic fragility curve for the performance levels of IO, LS, CP, and C decreases by $6.06 \%, 5.36 \%, 0.0 \%$, and $0.9 \%$, respectively, as compared to the results obtained for isolated structures. On the other side, the median $S_{a}\left(T_{1}\right)$ of the 5-story steel MRF for the performance levels of IO, LS, CP, and C decreases by $12.5 \%, 0.4 \%, 8.42 \%$, and $8.59 \%$, respectively, as compared to the results obtained for isolated structures.

According to Fig. 13, the median $S_{a}\left(T_{1}\right)$ of the 9-story RC MRF for the performance levels of IO and LS decreases by $0.1 \%$ and $2.4 \%$, respectively, but the performance levels of CP and C increase by $8.8 \%$ and $20.75 \%$, respectively. In contrast, the median $S_{a}\left(T_{1}\right)$ of the 5-story steel MRF for the performance levels of IO and LS increases by $16.66 \%$ and $3.17 \%$, respectively, while the performance levels of CP and C decrease by $13.68 \%$ and $15.74 \%$, respectively. So, we can see that the seismic probability of collapse for the 9-story RC MRF decreases because of pounding, whereas the seismic probability of collapse for the 5-story steel MRF increases, correspondingly.

A similar trend can be seen in Fig. 14, which presents the seismic fragility curves of the 5-story steel and the 5-story RC colliding structures. According to the results, the median $S_{a}\left(T_{1}\right)$ of the 5-story steel MRF for the performance levels of IO and LS increases by $3.87 \%$ and $8.33 \%$, respectively. However, the performance levels of CP and C decrease by $7.36 \%$ and $8.59 \%$, respectively. On the other side, the median $S_{a}\left(T_{1}\right)$ of the 5 -story RC MRF for the performance levels of IO decreases by $1.12 \%$, while the performance levels of LS, CP, and C increase by $1.51 \%, 8.1 \%$, and $13.13 \%$, respectively. 


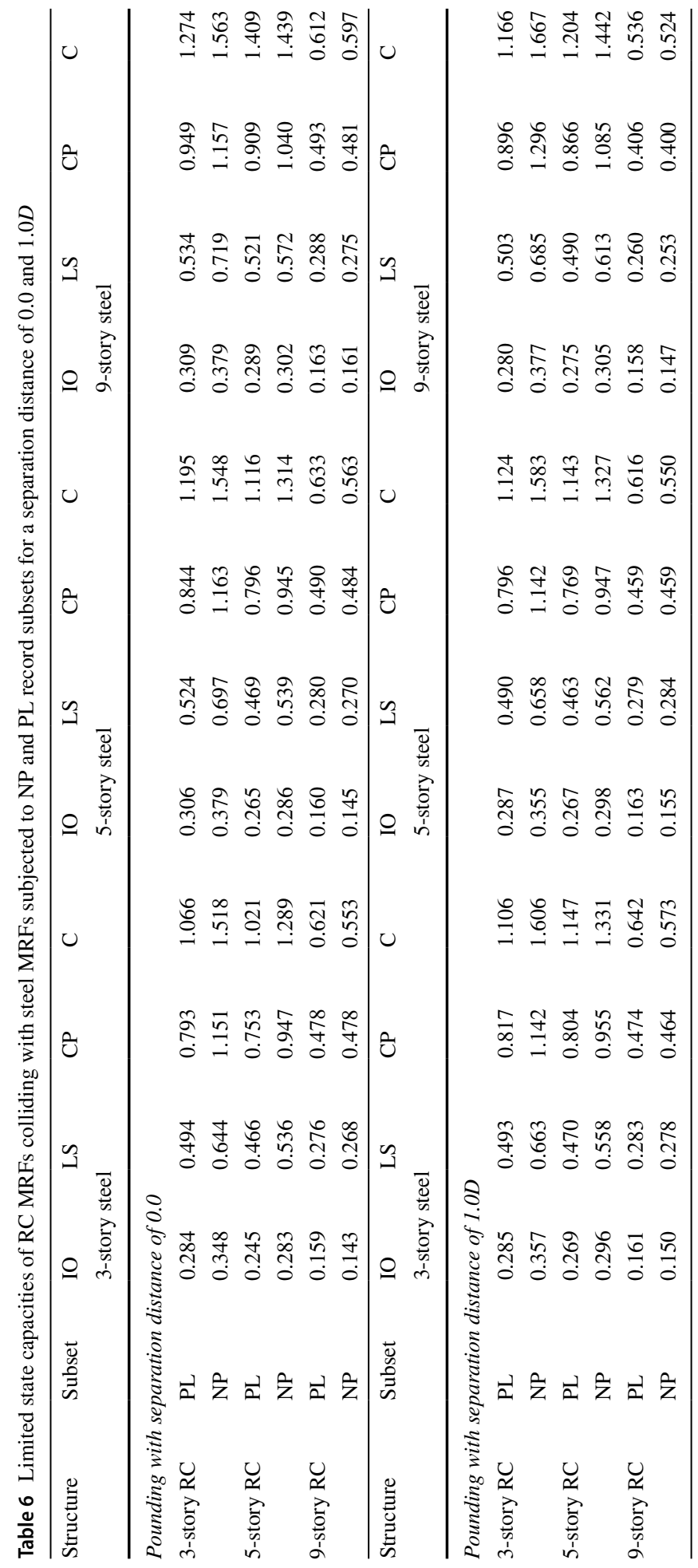



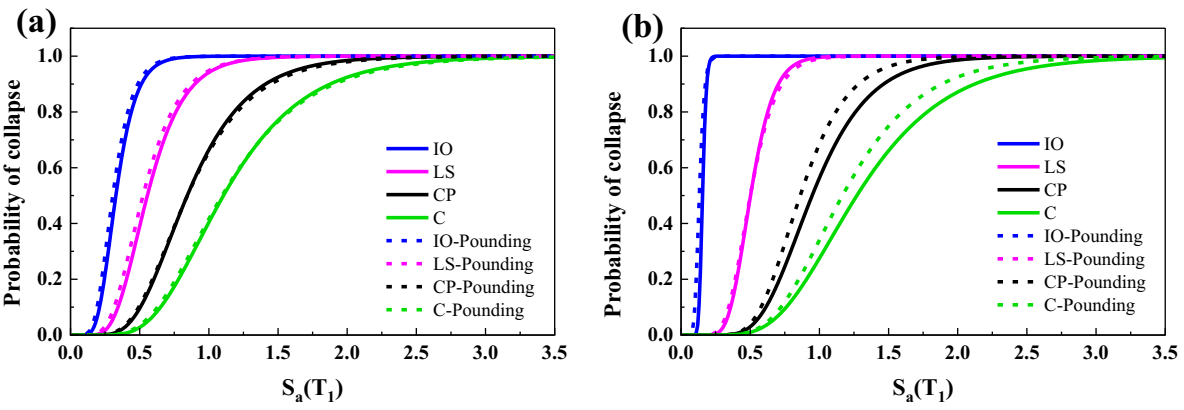

Fig. 12 Comparing the seismic fragility curves of a the 3 -story RC and $\mathbf{b}$ the 5 -story steel colliding structures for a separation distance of 0.0 subjected to the PL record subset
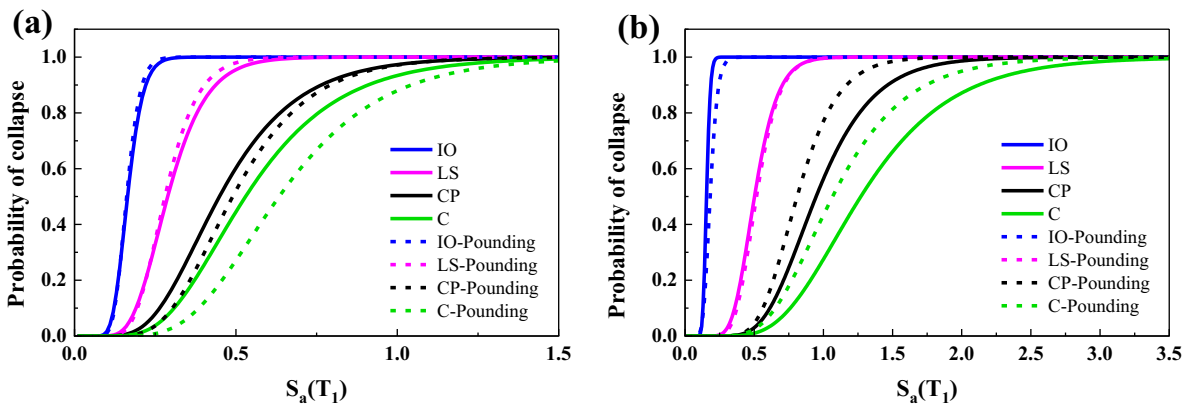

Fig. 13 Comparing the seismic fragility curves of $\mathbf{a}$ the 9-story RC and $\mathbf{b}$ the 5-story steel pounding structures for a separation distance of 0.0 subjected to the PL record subset
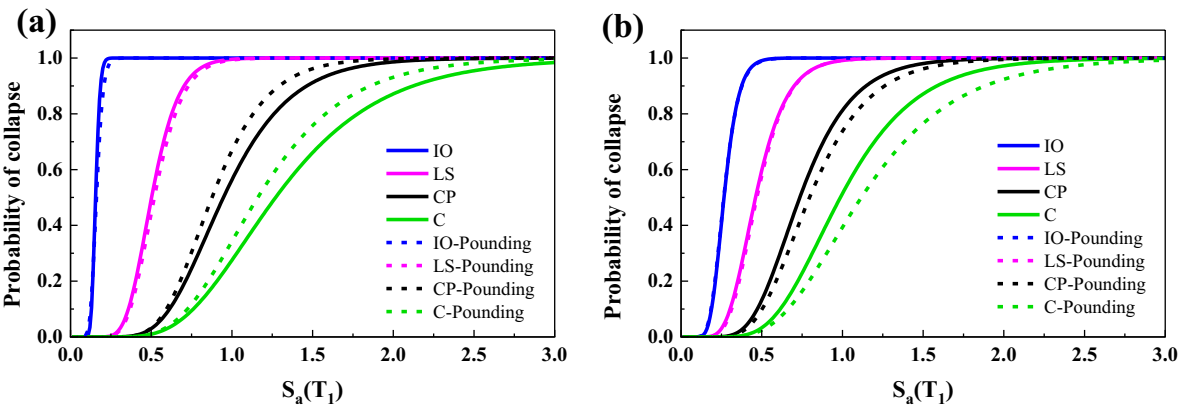

Fig. 14 Comparing the seismic fragility curves of a the 5-story steel and $\mathbf{b}$ the 5-story RC pounding structures for a separation distance of 0.0 subjected to the PL record subset

\subsubsection{Using supplemental FVDs}

According to the results presented in Tables 5 and 6, pounding can lead to an increase or decrease in seismic performance levels. Increasing the seismic performance level can be neglected due to a conservative assumption. On the other hand, the decrease in the seismic performance and the effects of pounding on the seismic response of both adjacent 
structures should be considered in the design process. In this section, the effects of FVDs, applied between floor levels of adjacent RC and steel MRFs (see Fig. 15), are investigated.

FVD is a passive energy dissipation device that dissipates seismic energy by executing the transformation of kinetic energy into heat energy. The damper force, $F_{F V D}$, depends on the relative velocity of damper ends and can be determined as follows (Patel and Jangid 2010; Kazemi et al. 2018b):

$$
F_{F V D}=C(\alpha)|\dot{x}|^{\alpha} \operatorname{sgn}(\dot{x})
$$

where $C(\alpha)$ is the damping coefficient, $\dot{x}$ stands for the relative velocity of damper ends, sgn is the signum function and $\alpha$ denotes the velocity exponent which takes values between 0.0 and 1.0 for nonlinear and linear FVD, respectively. Kandemir-Mazanoglu and Mazanoglu (2017) used a modified equation to calculate parameters of FVD installed between two adjacent structures. Equation (8) determines the supplemental damping ratio, $\xi_{F V D}$ (Kandemir-Mazanoglu and Mazanoglu 2017):

$$
\xi_{F V D}=\frac{\left(\max \left\{T_{1,1}, T_{1,2}\right\}\right) \sum_{j} C(\alpha)_{j}\left(\phi_{j, 1}-\phi_{j, 2}\right)^{2}}{4 \pi \sum_{i} m_{i} \phi_{i}^{2}}
$$

where $T_{1,1}, T_{1,2}$ is the fundamental period of the first and second structure, respectively, $\left(\phi_{j, 1}-\phi_{j, 2}\right)$ indicates the relative horizontal deformation between adjacent floor levels of structures corresponding to the first mode shape. Moreover, the relation between linear

Connected to the floor level of structure 1

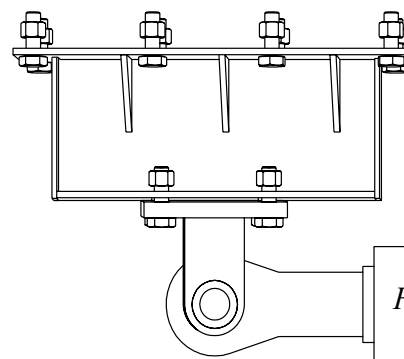

Fluid Viscous Damper
Connected to the floor level of structure 2

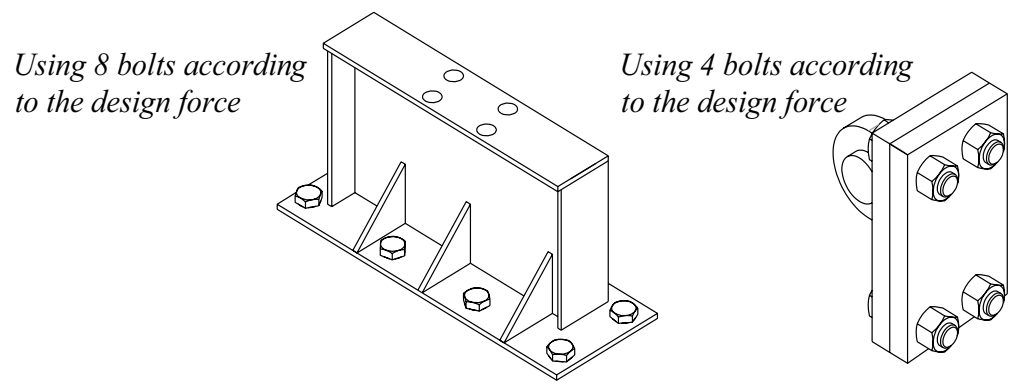

Fig. 15 Implemented FVD between the floor levels of the adjacent structures 
and nonlinear FVD can be determined based on the following equations (Patel and Jangid 2010; Kazemi et al. 2018b):

$$
\begin{gathered}
C(\alpha)=\frac{C(\alpha=1)\left(\min \left\{\omega_{1,1}, \omega_{1,2}\right\} X_{0}\right)^{1-\alpha}}{\beta} \\
\beta=\frac{2^{2+\alpha} \Gamma^{2}\left(1+\frac{\alpha}{2}\right)}{\pi \Gamma(2+\alpha)}
\end{gathered}
$$

where $C(\alpha=1)$ is the damper coefficient of linear FVD, $\omega_{1,1}$ and $\omega_{1,2}$ stand for the natural frequencies of the structures, $X_{0}$ is the maximum relative displacement response and $\Gamma$ is the gamma function. In order to investigate the effects of FVDs, the 3-story steel and 5 -story RC colliding MRFs were considered. The results obtained for a single beam and column of the first floor of the 3-story steel MRF considering two conditions of pounding with and without linear FVDs subjected to Kocaeli Turkey record (8/17/1999, Izmit) for $S_{a}\left(T_{1}\right)=1.34 \mathrm{~g}$ are shown in Fig. 16. It can be seen from the figure that using FVDs between structures can significantly reduce the maximum rotation of beam hinge from 0.051 to 0.026 radians, and the maximum rotation of column hinge from 0.048 to 0.016 radians. It can also be inferred that using FVDs decreases the moment-rotation of hinges leading to the decrease in the performance levels of the entire structure. It is worth mentioning that similar results have been obtained for all moment-rotation curves of the considered structural models with linear FVDs between them.

Figure 17 shows the results of using linear FVDs, with the supplemental damping ratio of 0.15 , between the 5-story RC and 3-story steel adjacent MRFs subjected to the PL record subset. It can be observed that pounding increases the median IDA curves of the 5-story RC MRF by 3.37\%. Moreover, applying FVDs between pounding floors level of the 5-story RC MRF with a separation distance of 0.0 and $1.0 D$ increases the median IDA curves by $9.41 \%$ and $19.09 \%$, respectively. On the other side, pounding decreases the median IDA curves of the 3-story steel MRF by $13.53 \%$ while, the median IDA curves of the 3-story steel MRF with FVDs in floors level are 1.09 and 1.14 times that obtained for 3 -story steel MRF in pounding condition, assuming separation distance equal to 0.0 and

(a)

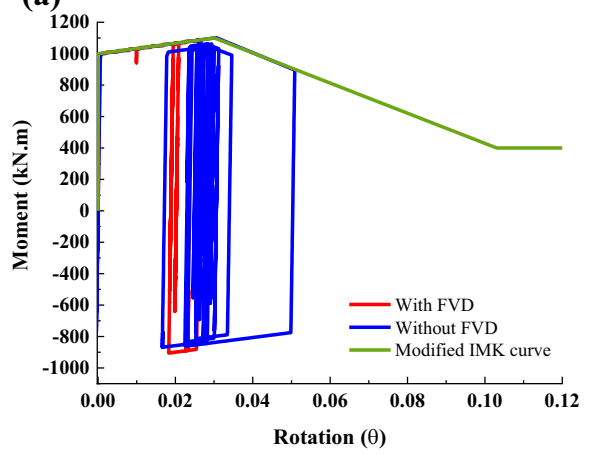

(b)

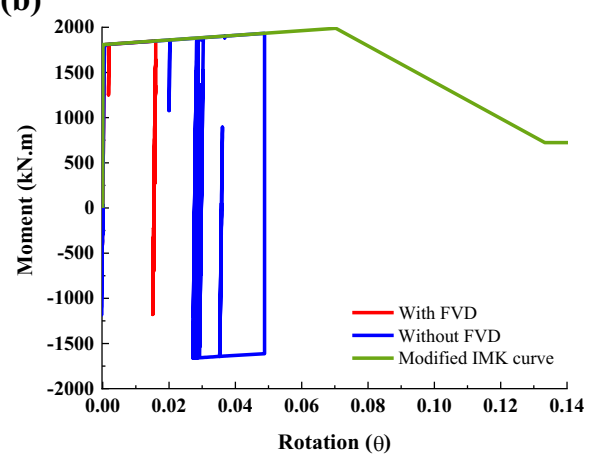

Fig. 16 Comparing hinges of a column, and $\mathbf{b}$ beam for first floor of the 3-story steel MRF considering pounding with 5-story RC MRF using linear FVDs between them, given a separation distance of 0.0 

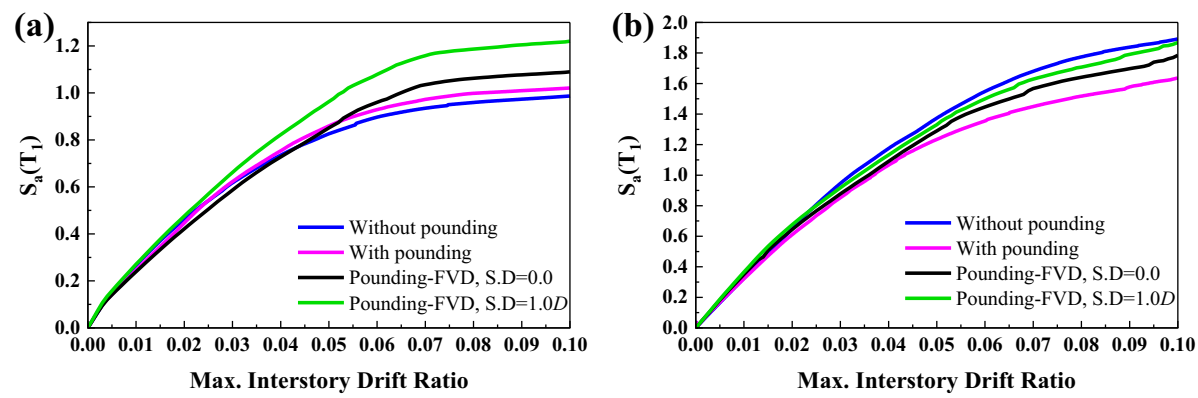

Fig. 17 Comparison of using linear FVDs, with the supplemental damping ratio of 0.15 , between a 5-story RC and b 3-story steel colliding structures subjected to the PL record subset

$1.0 D$, respectively. The same results are observed in Fig. 18 that compares structures using linear FVDs installed between the 9-story RC and 9-story steel adjacent MRFs subjected to the PL record subset. It can be seen from the figure that applying FVDs between floors level of the 9-story RC MRF with a separation distance of 0.0 and $1.0 D$, the median IDA curves increase by $18.43 \%$ and $22.47 \%$, respectively. Also, the median IDA curves increase by $6.52 \%$ and $11.9 \%$, respectively, for the case of using FVDs between pounding floors level of the 9-story steel MRF with a separation distance of 0.0 and $1.0 D$. Therefore, the results confirm that applying FVDs can enhance the seismic performance of both structures in the pounding conditions, and the supplemental damping ratio of FVDs leads to an increase in the median IDA curves.

\subsubsection{Modification factors}

The results of the study clearly indicate that pounding can lead to a decrease or increase in the performance levels. Also, the separation distance can play a key role. These effects cannot be considered during the design process of a structure using engineering software. To overcome this issue, some researchers (see Kazemi et al. 2020, for example) proposed modification factors for seismic collapse capacity estimation. In this paper, the modification factors are used to approximately estimate the performance levels of a structure considering pounding by dividing the limited state capacity values of pounding conditions to
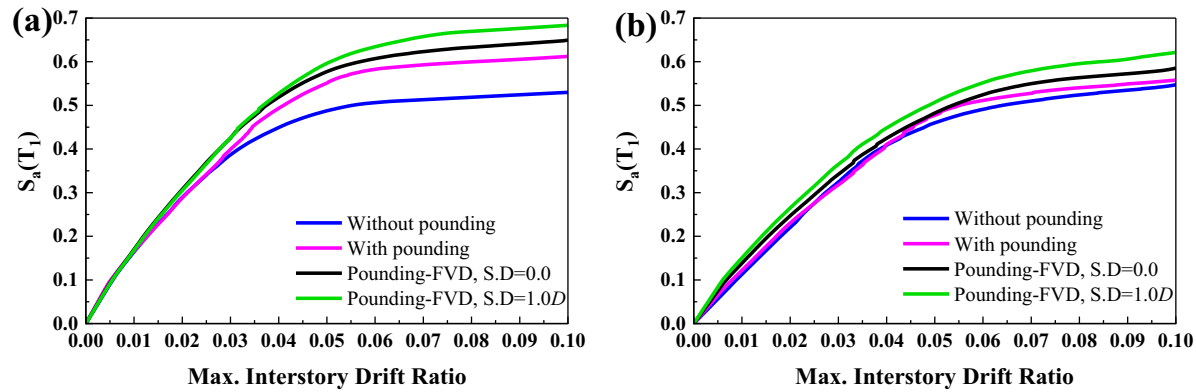

Fig. 18 Comparison of using FVDs with the supplemental damping ratio of 0.15 between a 9-story RC and b 9-story steel colliding structures subjected to the PL record subset 
the isolated ones. The modification factors of the steel MRFs colliding with RC MRFs subjected to the NP and the PL record subsets, for a separation distance of 0.0 and $1.0 \mathrm{D}$ are shown in Table 7. On the other hand, Table 8 presents the modification factors of the RC MRFs colliding with steel MRFs subjected to the NP and the PL record subsets, for a separation distance of 0.0 and $1.0 \mathrm{D}$. Using these modification factors can help engineers to modify the performance levels of the designed structure. The modification factor for the structural performance levels can be easily achieved to modify the analyzed structure under the selected record subset (e.g. for performance levels of IO, LS, CP, and C are 1.278, 0.937, 0.910 and 0.934, respectively, as shown in Table 7 for the PL record subset). It can be observed that the performance level of IO increases for the aforementioned example, while the performance level of $\mathrm{C}$ decreases, correspondingly. Thus, the engineer can easily find the effects of pounding on the designed structure. Moreover, these factors can be used for retrofitting of existing structures by considering the additional capacity caused by pounding.

\section{Conclusion}

The paper has been focused on predicting the performance levels of adjacent RC and steel structures under earthquake excitation. The effects of pounding on the seismic response of two adjacent structures have been evaluated and proper modification factors for already existing buildings and new ones have been determined. The 3-, 5-, and 9-story RC and steel MRFs have been considered assuming three separation distances between them $(0.0$, $0.5 D$, and $1.0 D$ ). For investigating the PL and NP effects of ground motions, two record subsets suggested by FEMA-P695 (2009) have been considered. Moreover, the influence of using FVDs between two structures has also been investigated. The results of the study are summarized as follows:

- The performance levels of RC MRFs subjected to the NP subset are higher than for the PL subset. The same results concern the 3-story steel MRF, while in the case of the 5-story steel MRF, only the performance level of $\mathrm{C}$ follows the trends for the 9-story steel MRF, and the seismic performance levels for PL subset are higher than for NP subset.

- The performance levels of the 5-story RC MRF colliding with 3-, 5-, and 9-story steel MRFs increase for all separation distances and two record subsets considered in the study. Moreover, due to the decrease in the performance levels of IO and LS, these performance levels are more vulnerable for considering the effects of pounding.

- Pounding increases the maximum rotation of beam and column hinges, which causes an increase in the performance level of structural members and the structure itself. The application of FVDs between floor levels of two adjacent structures can be effective in reduction of the maximum rotation of beams and columns. It can be considered as an alternative retrofitting method for existing buildings.

- The results for 5-story steel structure colliding with 3- and 9-story RC structures, which are in contact from the beginning, show that the performance levels of CP and C decrease by $8.42 \%, 8.59 \%, 13.68 \%$ and $15.74 \%$, respectively. In other words, the 3 - and 9-story RC structures cause the increase in the seismic collapse probability of adjacent 5-story steel structure. 


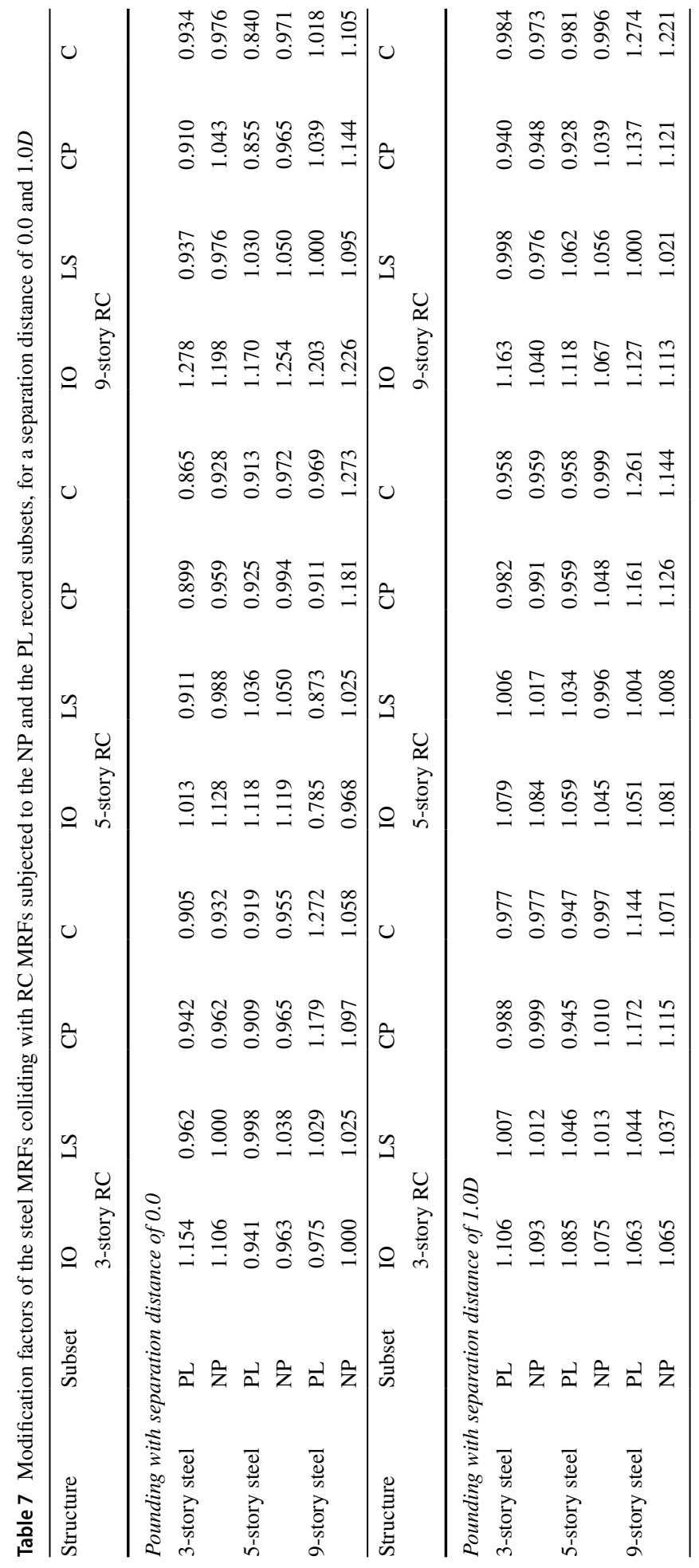




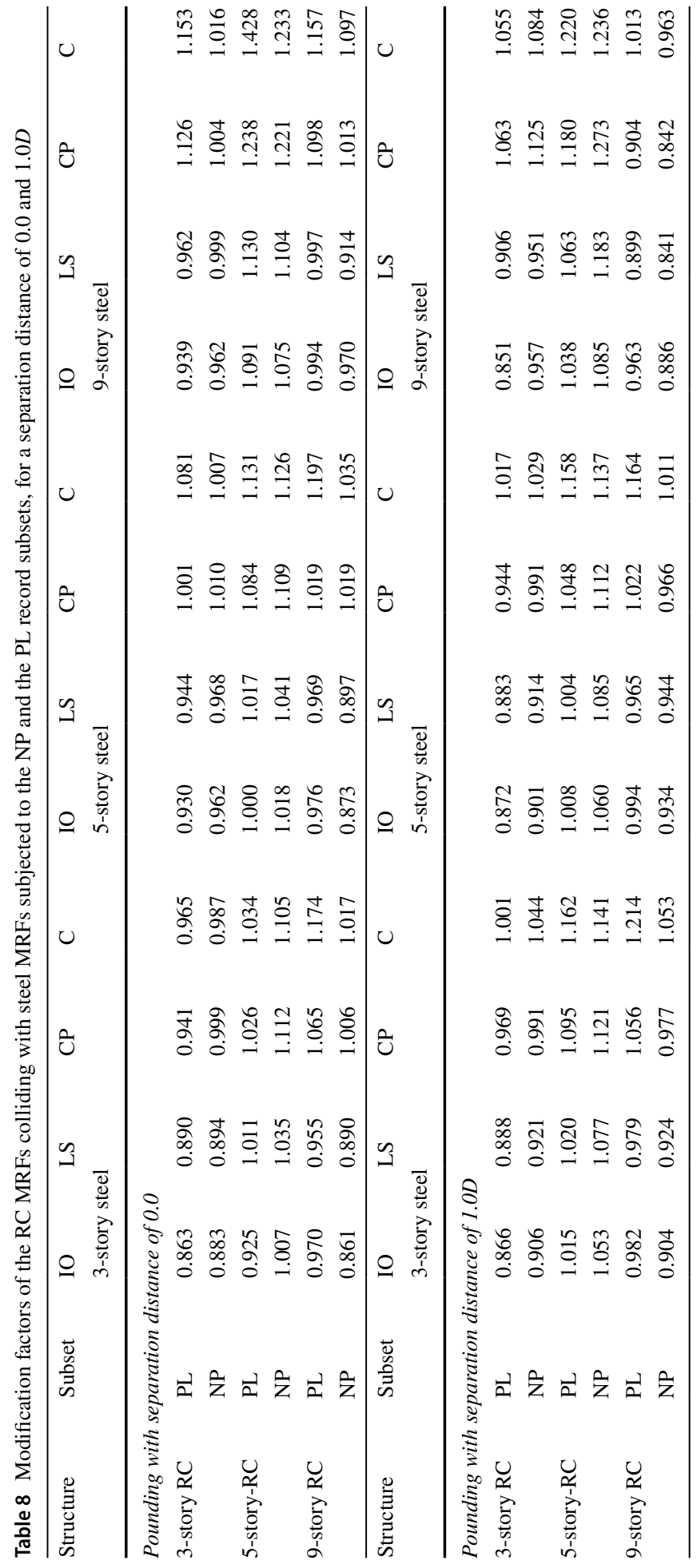


- Linear FVDs with the supplemental damping ratio of 0.15 between adjacent MRFs increase the median IDA curves of both structures. As a result, their seismic performance in pounding conditions improves correspondingly. Besides, increasing the supplemental damping ratio leads to an increase in the median IDA curves.

- The modification factors can be successfully used to modify the performance levels of the designed structures prone to pounding. Moreover, these factors can also be applied for retrofitting of existing structures by considering the additional capacity.

The analysis described in the paper has concerned the frame structures without any infills. Meanwhile, it has been confirmed that the incorporation of infills may change the structural behavior significantly (see Elwardany et al. 2019; Favvata et al. 2012; Favvata and Karayannis 2013 for example). Moreover, the effects of ductility and the shear force demands of the structural elements were not deeply investigated. Therefore, further studies are needed to be conducted so as to take into account the influence of other parameters and structural configurations.

Open Access This article is licensed under a Creative Commons Attribution 4.0 International License, which permits use, sharing, adaptation, distribution and reproduction in any medium or format, as long as you give appropriate credit to the original author(s) and the source, provide a link to the Creative Commons licence, and indicate if changes were made. The images or other third party material in this article are included in the article's Creative Commons licence, unless indicated otherwise in a credit line to the material. If material is not included in the article's Creative Commons licence and your intended use is not permitted by statutory regulation or exceeds the permitted use, you will need to obtain permission directly from the copyright holder. To view a copy of this licence, visit http://creativecommons.org/licenses/by/4.0/.

\section{References}

ACI Committee and International Organization for Standardization (2014) Building code requirements for structural concrete (ACI 318-14) and commentary. American Concrete Institute

AISC A (2016) AISC 341-10, seismic provisions for structural steel buildings. American Institute of Steel Construction, Chicago

AISC Committee (2016) Specification for structural steel buildings (ANSI/AISC 360-10). American Institute of Steel Construction, Chicago

Altoontash A (2004) Simulation and damage models for performance assessment of reinforced concrete beam-column joints. Doctoral dissertation, Stanford University.

Anagnostopoulos SA (1988) Pounding of buildings in series during earthquakes. Earthq Eng Struct Dyn 16(3):443-456. https://doi.org/10.1002/eqe.4290160311

Anagnostopoulos SA (2004) Equivalent viscous damping for modeling inelastic impacts in earthquake pounding problems. Earthq Eng Struct Dyn 33(8):897-902

Anagnostopoulos SA, Karamaneas CE (2008a) Use of collision shear walls to minimize seismic separation and to protect adjacent buildings from collapse due to earthquake-induced pounding. Earthq Eng Struct Dyn 37(12):1371-1388

Anagnostopoulos SA, Karamaneas CE (2008b) Collision shear walls to mitigate seismic pounding of adjacent buildings. In: 14 WCEE: 14th world conference on earthquake engineering conference proceedings

Applied Technology Council and United States, Federal Emergency Management Agency (2009) Quantification of building seismic performance factors. US Department of Homeland Security, FEMA

ASCE/SEI 7-16 (2017) Minimum design loads and associated criteria for buildings and other structures. American Society of Civil Engineers, Reston

Asgarkhani N, Yakhchalian M, Mohebi B (2020) Evaluation of approximate methods for estimating residual drift demands in BRBFs. Eng Struct 224:110849 
Barros RC, Khatami SM (2012) Seismic response effect of shear walls in reducing pounding risk of reinforced concrete buildings subjected to near-fault ground motions. In: Proceedings of the 15th world conference on earthquake engineering. Lisbon, Portugal

Bekdaş G, Nigdeli SM (2012) Preventing the pounding of adjacent buildings with harmony search optimized tuned mass damper. In: 3rd European conference of civil engineering, pp 2-4

Chenna R, Ramancharla PK (2018) Damage assessment due to pounding between adjacent structures with equal and unequal heights. J Civ Struct Health Monit 8(4):635-648

Cole G, Dhakal RP, Carr AJ, Bull D (2010) Building pounding state of the art: identifying structures vulnerable to pounding damage. In: Proceedings of New Zealand society for earthquake engineering annual conference

Cole GL, Dhakal RP, Turner FM (2012) Building pounding damage observed in the 2011 Christchurch earthquake. Earthq Eng Struct Dyn 41(5):893-913

Deierlein GG, Haselton CB (2005) Benchmarking the collapse safety of code-compliant reinforced concrete moment frame building systems. In: ATC/JSCA US-Japan workshop on improvement of structural design and construction practices, proceedings of an international workshop, pp 17-19

Dimitrakopoulos E, Makris N, Kappos AJ (2009) Dimensional analysis of the earthquake-induced pounding between adjacent structures. Earthq Eng Struct Dyn 38(7):867-886

Dimitrakopoulos E, Makris N, Kappos AJ (2010) Dimensional analysis of the earthquake response of a pounding oscillator. J Eng Mech 136(3):299-310

Efraimiadou S, Hatzigeorgiou GD, Beskos DE (2013) Structural pounding between adjacent buildings subjected to strong ground motions. Part I: the effect of different structures arrangement. Earthq Eng Struct Dyn 42(10):1509-1528

Elwardany H, Seleemah A, Jankowski R, El-Khoriby S (2019) Influence of soil-structure interaction on seismic pounding between steel frame buildings considering the effect of infill panels. Bull Earthq Eng 17(11):6165-6202

Favvata MJ (2017) Minimum required separation gap for adjacent RC frames with potential inter-story seismic pounding. Eng Struct 152:643-659

Favvata MJ, Karayannis CG (2013) The inter-story pounding effect on the seismic behavior of infilled and pilotis RC structures. In: Proceedings of the 6th European workshop on the "seismic behaviour of irregular and complex structures". Haifa, Israel, paper no. 38, geotechnical, geological and earthquake engineering, vol 24. pp 87-101

Favvata MJ, Karayannis CG, Anagnostopoulou V (2012) Influence of infill panels with and without openings on the pounding effect of RC structures, In: Proceedings of the 15th world conference on earthquake engineering. Lisbon, Portugal, paper no. 3647

Favvata MJ, Naoum MC, Karayannis CG (2013) Earthquake induced interaction between RC frame and steel frame structures. WIT Trans Built Environ 134:839-851

FEMA-356 (2000) Prestandard and commentary for the seismic rehabilitation of buildings. Federal Emergency Management Agency, Washington.

Hameed A, Saleem M, Qazi AU, Saeed S, Bashir MA (2012) Mitigation of seismic pounding between adjacent buildings. Pak J Sci 64(4):326

Haselton CB, Deierlein GG (2007) Assessing seismic collapse safety of modern reinforced concrete frame buildings. PEER report, 8

Ibarra LF, Medina RA, Krawinkler H (2005) Hysteretic models that incorporate strength and stiffness deterioration. Earthq Eng Struct Dyn 34(12):1489-1511

Jamal KA, Vidyadhara HS (2013) Seismic pounding of multistoreyed buildings. Moment 15(2) :12-17

Jankowski R (2010) Experimental study on earthquake-induced pounding between structural elements made of different building materials. Earthq Eng Struct Dyn 39(3):343-354

Jankowski R, Mahmoud S (2016) Linking of adjacent three-storey buildings for mitigation of structural pounding during earthquakes. Bull Earthq Eng 14(11):3075-3097

Jeng V, Tzeng WL (2000) Assessment of seismic pounding hazard for Taipei City. Eng Struct 22(5):459-471

Kandemir-Mazanoglu EC, Mazanoglu K (2017) An optimization study for viscous dampers between adjacent buildings. Mech Syst Signal Process 89:88-96

Karayannis CG, Favvata MJ (2005) Earthquake-induced interaction between adjacent reinforced concrete structures with non-equal heights. Earthq Eng Struct Dyn 34(1):1-20

Karayannis CG, Naoum MC (2018) Torsional behavior of multistory RC frame structures due to asymmetric seismic interaction. Eng Struct 163:93-111

Kazemi F, Mohebi B, Yakhchalian M (2018a) Evaluation the P-delta effect on collapse capacity of adjacent structures subjected to far-field ground motions. Civ Eng J 4(5):1066. https://doi.org/10.28991/ cej-0309156 
Kazemi F, Mohebi B, Yakhchalian M (2018b) Enhancing the seismic performance of adjacent pounding structures using viscous dampers. In: The 16th European conference on earthquake engineering (16ECEE), pp 18-21

Kazemi F, Mohebi B, Yakhchalian M (2020) Predicting the seismic collapse capacity of adjacent structures prone to pounding. Can J Civ Eng 47(6):663-677

Kitayama S, Constantinou MC (2018) Seismic performance of buildings with viscous damping systems designed by the procedures of ASCE/SEI 7-16. J Struct Eng 144(6):04018050

Leibovich E, Rutenberg A, Yankelevsky DZ (1996) On eccentric seismic pounding of symmetric buildings. Earthq Eng Struct Dyn 25(3):219-233

Licari M, Sorace S, Terenzi G (2015) Nonlinear modeling and mitigation of seismic pounding between R/C frame buildings. J Earthq Eng 19(3):431-460

Lignos DG, Krawinkler H (2010) Deterioration modeling of steel components in support of collapse prediction of steel moment frames under earthquake loading. J Struct Eng 137(11):1291-1302

Lin JH, Weng CC (2001) Spectral analysis on pounding probability of adjacent buildings. Eng Struct 23(7):768-778

Mahmoud S, Jankowski R (2009) Elastic and inelastic multi-storey buildings under earthquake excitation with the effect of pounding. J Appl Sci 9(18):3250-3262

Mahmoud S, Jankowski R (2011) Modified linear viscoelastic model of earthquake-induced structural pounding. Iran J Sci Technol Trans Civ Eng 35(C1):51-62

Mahmoud S, Chen X, Jankowski R (2008) Structural pounding models with Hertz spring and nonlinear damper. J Appl Sci 8(10):1850-1858

MATLAB/Simulink as a Technical Computing Language (2014) Engineering computations and modeling in MATLAB

McKenna F, Fenves GL, Filippou FC, Scott MH (2016) Open system for earthquake engineering simulation (OpenSees). Pacific Earthquake Engineering Research Center, University of California, Berkeley. http://OpenSees.berkeley.edu

Miari M, Choong KK, Jankowski R (2019) Seismic pounding between adjacent buildings: identification of parameters, soil interaction issues and mitigation measures. Soil Dyn Earthq Eng 121:135-150

Miari M, Choong KK, Jankowski R (2020) Seismic pounding between bridge segments: a stateof-the-art review. Archiv Comput Methods Eng. https://doi.org/10.1007/s11831-019-09389-X (publishedonline13.01.2020)

Mohebi B, Kazemi F, Yakhchalian M (2018) Investigating the P-Delta effects on the seismic collapse capacity of adjacent structures. In: 16th European conference on earthquake engineering (16ECEE), 18-21, June, Thessaloniki, Greece

Mohebi B, Yazdanpanah O, Kazemi F, Formisano A (2020) Seismic damage diagnosis in adjacent steel and RC MRFs considering pounding effects through improved wavelet-based damage-sensitive feature. J Build Eng 33:101847

Nair N (2016) Evaluation of seismic pounding between adjacent RC buildings. Int J Eng Res Technol 3(4):138-147

Patel CC, Jangid RS (2010) Seismic response of dynamically similar adjacent structures connected with viscous dampers. IES J Part A Civ Struct Eng 3(1):1-13

Polycarpou PC, Komodromos P (2010) Earthquake-induced poundings of a seismically isolated building with adjacent structures. Eng Struct 32(7):1937-1951

Polycarpou PC, Komodromos P, Polycarpou AC (2013) A nonlinear impact model for simulating the use of rubber shock absorbers for mitigating the effects of structural pounding during earthquakes. Earthq Eng Struct Dyn 42(1):81-100

Polycarpou PC, Papaloizou L, Komodromos P (2014) An efficient methodology for simulating earthquakeinduced 3D pounding of buildings. Earthq Eng Struct Dyn 43(7):985-1003

Pratesi F, Sorace S, Terenzi G (2013) Seismic pounding mitigation of a modern heritage R/C bell tower. WIT Trans Built Environ WIT Press 131:303-314

Pratesi F, Sorace S, Terenzi G (2014) Analysis and mitigation of seismic pounding of a slender R/C bell tower. Eng Struct 71:23-34

Raheem SEA, Fooly MY, Shafy AGA, Taha AM, Abbas YA, Latif MMA (2019) Numerical simulation of potential seismic pounding among adjacent buildings in series. Bull Earthq Eng 17(1):439-471

Rezaei H, Moayyedi SA, Jankowski R (2020) Probabilistic seismic assessment of RC box-girder highway bridges with unequal-height piers subjected to earthquake-induced pounding. Bull Earthq Eng 18(4):1547-1578

Rezavani A, Moghadam AS (2004) Using shaking table to study different methods of reduceing effects of buildings pounding during earthquake. In: 13th World conference on earthquake engineering, paper (no. 698) 
Rezavandi A, Moghadam AS (2007) Experimental and numerical study on pounding effects and mitigation techniques for adjacent structures. Adv Struct Eng 10(2):121-134

Salman APDMM, Al-Amawee EAH (2006) The ratio between static and dynamic modulus of elasticity in normal and high strength concrete. J Eng Sustain Dev 10(2):163-174

Skrekas P, Sextos A, Giaralis A (2014) Influence of bi-directional seismic pounding on the inelastic demand distribution of three adjacent multi-storey R/C buildings. Earthq Struct 6(1):71-87

Sołtysik B, Jankowski R (2013) Non-linear strain rate analysis of earthquake-induced pounding between steel buildings. Int J Earth Sci Eng 6(3):429-433

Sołtysik B, Falborski T, Jankowski R (2017) Preventing of earthquake-induced pounding between steel structures by using polymer elements — experimental study. Procedia Eng 199:278-283

Sołtysik B, Falborski T, Jankowski R (2020) Study on polymer elements for mitigation of earthquakeinduced pounding between buildings in complex arrangements. In: Seismic behaviour and design of irregular and complex civil structures III, geotechnical, geological and earthquake engineering, vol 48. Springer, Cham, pp 391-401

Sorace S, Terenzi G (2013) Damped interconnection-based mitigation of seismic pounding between adjacent R/C buildings. Int J Eng Technol 5(3):406

Takabatake H, Yasui M, Nakagawa Y, Kishida A (2014) Relaxation method for pounding action between adjacent buildings at expansion joint. Earthq Eng Struct Dyn 43(9):1381-1400

Tubaldi E, Barbato M, Ghazizadeh S (2012) A probabilistic performance-based risk assessment approach for seismic pounding with efficient application to linear systems. Struct Saf 36:14-22

Vamvatsikos D, Cornell CA (2002) Incremental dynamic analysis. Earthq Eng Struct Dyn 31(3):491-514

Yakhchalian M, Asgarkhani N, Yakhchalian M (2020) Evaluation of deflection amplification factor for steel buckling restrained braced frames. J Build Eng 30:101228

Publisher's Note Springer Nature remains neutral with regard to jurisdictional claims in published maps and institutional affiliations. 